\title{
O gênero Pinnularia Ehrenberg (Bacillariophyceae) em um lago de inundação do rio Tapajós (Lago Verde, Santarém, Pará, Brasil)'
}

\author{
Raieli Carvalho Rêgo Liberal ${ }^{*}\left(\right.$ D), Lezilda Carvalho Torgan ${ }^{3}$ (D), Sérgio Melo ${ }^{2}$ (D), \\ Andreia Cavalcante Pereira ${ }^{2}$
}

\author{
'Parte da dissertação de mestrado da primeira autora, Programa de Pós-Graduação em Recursos Aquáticos \\ Continentais Amazônicos, Universidade Federal do Oeste do Pará. \\ 2Universidade Federal do Oeste do Pará, Instituto de Ciências e Tecnologia das Águas. Av. Vera Paz, s/n, Bairro Salé, CEP 68.040-255, \\ Santarém, Pará, Brasil. carvalhoraieli@ymail.com, melo.joaopedro@gmail.com, diatomaceas@gmail.com \\ ${ }^{3}$ Secretaria do Meio Ambiente e Infraestrutura, Museu de Ciências Naturais, Rio Grande do Sul, \\ Porto Alegre 90690-000, Brasil. lezilda.torgan@gmail.com \\ *Autor para correspondência: carvalhoraieli@ymail.com
}

RESUMO - O presente estudo teve como objetivo realizar o inventário taxonômico do gênero Pinnularia no Lago Verde, um lago de inundação localizado na margem direita do rio Tapajós na Área de Proteção Ambiental Alter do Chão no município de Santarém. As amostragens foram realizadas mensalmente, com rede de plâncton $(20 \mu \mathrm{m})$ em quatro estações amostrais, incluindo zona limnética e litoral do lago, de julho de 2016 a junho de 2017. Foram identificados 41 táxons infragenéricos, sendo 29 espécies e 12 variedades, os quais foram descritos, comentados e ilustrados em microscópio óptico e/ou eletrônico de varredura. Destes, Pinnularia acuminata var. novazealandica Krammer, $P$. divergens var. media Krammer, $P$. graciloides var. rumrichae Krammer, P. parallela var. parallela Brun, P. percuneata var. percuneata Krammer e P. tumescens Metzeltin \& Krammer são registrados pela primeira vez para a Amazônia brasileira e 21 são documentados pela primeira vez para o estado do Pará.

Palavras-chave: Amazônia, águas claras, diatomáceas, taxonomia

ABSTRACT - The genus Pinnularia Ehrenberg (Bacillariophyceae) in a floodplain lake of the Tapajós river (Verde Lake, Santarém, Pará, Brazil). This study aimed to carry out a taxonomic inventory of the genus Pinnularia in Verde Lake, a floodplain lake located on the right bank of the Tapajós River, in the Protection Area of Alter do Chão in Santarém. Samplings were carried out monthly using a plankton net (20 $\mu \mathrm{m})$ at four different stations, including limnetic and littoral zones, from July 2016 to June 2017. A total of 41 taxa, of which 29 species and 12 varieties were described, commented and illustrated with light microscopy and/or scanning electron microscopy micrographs. Pinnularia acuminata var. novazealandica Krammer, P. divergens var. media Krammer, P. graciloides var. rumrichae Krammer, P. parallela var. parallela Brun, P. percuneata var. percuneata Krammer and $P$. tumescens Metzeltin \& Krammer are the first records for the Brazilian Amazon and 21 are documented for the first time for Pará State.

Keywords: Amazon, clear water, diatoms, taxonomy

\section{INTRODUÇÃO}

A família Pinnulariaceae Mann é composta por diatomáceas caracterizadas por indivíduos solitários que apresentam estrias de estrutura alveolada (Round et al. 1990). Atualmente, quatro gêneros, Diatomella Greville, Hygropetra Krammer \& Lange-Bertalot, Oestrupia Heiden ex Hustedt e Pinnularia Ehrenberg constituem a família (Kociolek et al. 2020). Dentre estes, o gênero Pinnularia é o mais rico em espécies na família, apresentando mais de 2.500 táxons registrados no Algaebase, dos quais 748 são atualmente aceitos (Guiry \& Guiry 2020). O gênero é epipélico e ocorre em habitats de água doce com condições oligotróficas e com reduzidos valores de $\mathrm{pH}$ (Round et al. 1990, Krammer 2000).
Os estudos que incluem o gênero Pinnularia na Amazônia brasileira estão, em sua maioria, concentrados no Estado do Amazonas, em ambientes de águas pretas, tais como o rio Negro (Uherkovich 1976, Fukushima \& Xavier 1988, Wetzel 2011, Metzeltin \& Lange-Bertalot 1998, 2007, Pereira et al. 2012, 2017), rio Jaú (DíazCastro et al. 2003), Lago Tupé (Pereira et al. 2013, 2014, 2015), Lago Cutiuaú (Raupp et al. 2009). Em ambientes de águas claras poucos estudos foram realizados, como as contribuições para os rios Arapiuns e Tapajós, lago Jurucuí e igarapé do Tento (Hustedt 1965, Uherkovich 1976, Metzeltin \& Lange-Bertalot 1998, 2007). Embora os estudos supracitados tenham acrescido importantes informações ao conhecimento taxonômico sobre as espécies do gênero Pinnularia, as investigações ainda 
não são suficientes considerando a extensão e diversidade de ambientes aquáticos da Bacia Amazônica.

O conhecimento da diversidade e distribuição deste grupo em lagos de inundação é de grande importância porque poderá servir como base para futuros estudos ecológicos e de biomonitoramento. Dessa forma, com o intuito de ampliar o conhecimento sobre a flora de Pinnularia em ambientes amazônicos de águas claras, o presente estudo teve como objetivo realizar o inventário taxonômico do gênero presente no plâncton de um lago de inundação da bacia do rio Tapajós.

\section{MATERIAL E MÉTODOS}

O lago Verde está localizado na margem direita do rio Tapajós $\left(02^{\circ} 31^{\prime} 0^{\prime \prime}\right.$ e $2^{\circ} 28^{\prime} 0$ " 'S e $54^{\circ} 58^{\prime} 0^{\prime \prime}$ " e $54^{\circ} 54^{\prime}$ 0 " W) na Área de Proteção Ambiental Alter do Chão, a aproximadamente $40 \mathrm{~km}$ da cidade de Santarém, Estado do Pará (Fig. 1). Para o presente estudo foram demarcadas quatro estações amostrais, sendo uma na área central do lago, estação CL $\left(02^{\circ} 29^{\prime \prime} 26,7^{\prime}\right.$ 'S e $54^{\circ} 56^{\prime \prime}$ "52,6' W) e, três em regiões próximas ao aporte de água de três pequenos igarapés (riachos), estação IM - Igarapé do Macaco ( $02^{\circ} 28^{\prime \prime}$ $43,8^{\prime} \mathrm{S}$ e $\left.54^{\circ} 56^{\prime \prime} 06,9^{\prime} \mathrm{W}\right)$; IMe - Igarapé do Meiratiapina $\left(02^{\circ} 29^{\prime \prime} 09,3^{\prime} \mathrm{S}\right.$ e $\left.54^{\circ} 56^{\prime \prime} 53,9^{\prime} \mathrm{W}\right)$; e IC- Igarapé do Camarão ( $02^{\circ} 30^{\prime \prime} 04,3^{\prime}$ 'S e $54^{\circ} 56^{\prime \prime}$ " $06,1^{\prime}$ 'W).

As amostragens foram realizadas mensalmente, de julho de 2016 a junho de 2017, com rede de plâncton, malha de $20 \mu \mathrm{m}$, através de arrastos verticais e horizontais. Foram coletadas 48 amostras, armazenadas em frascos de $100 \mathrm{~mL}$ e fixadas com solução de Transeau (Bicudo \& Menezes 2006), as quais estão depositadas no Herbário da Universidade Federal do Oeste do Pará - HSTM (Tab. 1).

Para o estudo, parte de cada amostra foi submetida ao processo de oxidação seguindo o método de Stosch (1970). Após esse processo, foi efetuado a montagem de lâminas permanentes com alíquotas do material oxidado utilizando a resina Naphrax $(I R=1,74)$ como meio de inclusão para a observação do material em microscopia óptica. Para a observação em microscopia eletrônica de varredura foi efetuada a montagem do material oxidado em lâminas de raios-X sobre suporte de alumínio, seco em estufa e metalizado com $30 \mathrm{~nm}$ de ouro no equipamento BALTEC SCD005. Para observação e registro do material foram utilizados microscópio óptico (MO) Zeiss modelo Axioscope A1 em aumento de 1000x com sistema de captura de imagem modelo AxioCam ERC5s, e microscópio eletrônico de varredura (MEV) JEOL JSM-6060. O sistema de classificação adotado foi o de Round et al. (1990).

A identificação das espécies de Pinnularia foi baseada nas características morfológicas e morfométricas da frústula, tendo como base, sempre que possível, a obra original ou aquelas como a de Schmidt et al. (1874-1959), Hustedt (1965), Patrick \& Reimer (1966), Simonsen (1987), Krammer (2000), Metzeltin \& Lange-Bertalot $(1998,2007)$, bem como, artigos que tratam do gênero. Foram apresentadas descrições taxonômicas para os táxons citados pela primeira vez para a Amazônia brasileira ou para o Estado do Pará.

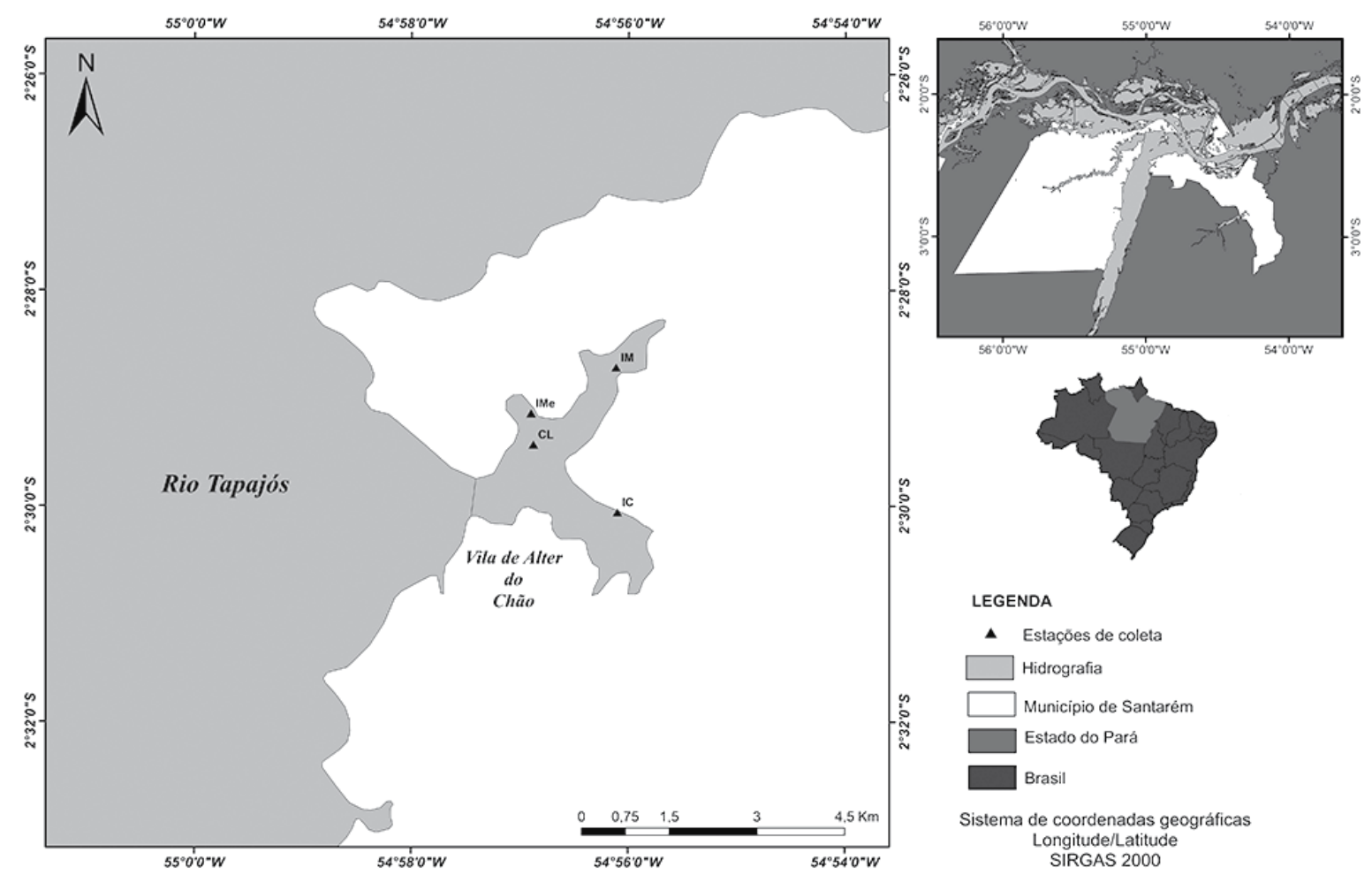

Fig. 1. Localização geográfica do Lago Verde, indicando as quatro estações amostrais, no município de Santarém no estado do Pará. IM = Igarapé do $\mathrm{Macaco}, \mathrm{IMe}=$ Igarapé do Meiritiapina, $\mathrm{CL}=$ região Central do Lago, $\mathrm{IC}=$ Igarapé do Camarão. 
Tabela 1. Referência do material examinado no lago Verde depositado no Herbário da Universidade Federal do Oeste do Pará (HSTM-UFOPA) com o respectivo local de amostragem: IM = Igarapé do Macaco, IMe = Igarapé do Meiratiapina, CL= Central do Lago, IC = Igarapé do Camarão.

\begin{tabular}{|c|c|c|c|}
\hline Material examinado & Data & Local & Coletor \\
\hline HSTM - Algas 10292 & 09/VII/2016 & IC & Carvalho, R. s/n ${ }^{\circ}$ \\
\hline HSTM - Algas 10293 & $10 / \mathrm{II} / 2017$ & IC & Carvalho, R. s/n ${ }^{\circ}$ \\
\hline HSTM - Algas 10294 & $17 / \mathrm{XI} / 2016$ & IC & Carvalho, R. s/no \\
\hline HSTM - Algas 10295 & 06/XII/2016 & IC & Carvalho, R. s/n ${ }^{\circ}$ \\
\hline HSTM - Algas 10296 & $04 / \mathrm{X} / 2016$ & IC & Carvalho, R. s/n ${ }^{\circ}$ \\
\hline HSTM - Algas 10297 & 09/IX/2016 & IC & Carvalho, R. s/no \\
\hline HSTM - Algas 10298 & 11/VIII/2016 & IC & Carvalho, R. s/n ${ }^{\circ}$ \\
\hline HSTM - Algas 10299 & 04/I/2017 & IC & Carvalho, R. s/n ${ }^{\circ}$ \\
\hline HSTM - Algas 10300 & $10 / \mathrm{III} / 2017$ & IC & Carvalho, R. s/n ${ }^{\circ}$ \\
\hline HSTM - Algas 10301 & 07/IV/2017 & IC & Carvalho, R. s/n ${ }^{\circ}$ \\
\hline HSTM - Algas 10302 & $11 / \mathrm{V} / 2017$ & IC & Carvalho, R. s/no \\
\hline HSTM - Algas 10303 & $09 / \mathrm{VI} / 2017$ & IC & Carvalho, R. s/n ${ }^{\circ}$ \\
\hline HSTM - Algas 10304 & $04 / \mathrm{X} / 2016$ & $\mathrm{CL}$ & Carvalho, R. s/n ${ }^{\circ}$ \\
\hline HSTM - Algas 10305 & 09/VII/2016 & CL & Carvalho, R. s/n ${ }^{\circ}$ \\
\hline HSTM - Algas 10306 & $10 / \mathrm{II} / 2017$ & $\mathrm{CL}$ & Carvalho, R. s/n ${ }^{\circ}$ \\
\hline HSTM - Algas 10307 & $17 / \mathrm{XI} / 2016$ & $\mathrm{CL}$ & Carvalho, R. s/n ${ }^{\circ}$ \\
\hline HSTM - Algas 10308 & 06/XII/2016 & $\mathrm{CL}$ & Carvalho, R. s/n ${ }^{\circ}$ \\
\hline HSTM - Algas 10309 & 11/VIII/2016 & CL & Carvalho, R. s/n ${ }^{\circ}$ \\
\hline HSTM - Algas 10310 & 09/IX/2016 & $\mathrm{CL}$ & Carvalho, R. s/n ${ }^{\circ}$ \\
\hline HSTM - Algas 10311 & $04 / \mathrm{I} / 2017$ & $\mathrm{CL}$ & Carvalho, R. s/n ${ }^{\circ}$ \\
\hline HSTM - Algas 10312 & 10/III/2017 & CL & Carvalho, R. s/n ${ }^{\circ}$ \\
\hline HSTM - Algas 10313 & 07/IV/2017 & $\mathrm{CL}$ & Carvalho, R. s/n ${ }^{\circ}$ \\
\hline HSTM - Algas 10314 & $11 / \mathrm{V} / 2017$ & CL & Carvalho, R. s/n ${ }^{\circ}$ \\
\hline HSTM - Algas 10315 & 09/VI/2017 & $\mathrm{CL}$ & Carvalho, R. s/n ${ }^{\circ}$ \\
\hline HSTM - Algas 10316 & $10 / \mathrm{II} / 2017$ & IM & Carvalho, R. s/n ${ }^{\circ}$ \\
\hline HSTM - Algas 10317 & 06/XII/2016 & IM & Carvalho, R. s/n ${ }^{\circ}$ \\
\hline HSTM - Algas 10318 & 09/VII/2016 & IM & Carvalho, R. s/n ${ }^{\circ}$ \\
\hline HSTM - Algas 10319 & $04 / \mathrm{X} / 2016$ & IM & Carvalho, R. s/n ${ }^{\circ}$ \\
\hline HSTM - Algas 10320 & $17 / \mathrm{XI} / 2016$ & IM & Carvalho, R. s/n ${ }^{\circ}$ \\
\hline HSTM - Algas 10321 & 11/VIII/2016 & IM & Carvalho, R. s/n ${ }^{\circ}$ \\
\hline HSTM - Algas 10322 & 09/IX/2016 & IM & Carvalho, R. s/n ${ }^{\circ}$ \\
\hline HSTM - Algas 10323 & $10 / \mathrm{III} / 2017$ & IM & Carvalho, R. s/n ${ }^{\circ}$ \\
\hline HSTM - Algas 10324 & 04/I/2017 & IM & Carvalho, R. s/n ${ }^{\circ}$ \\
\hline HSTM - Algas 10325 & 07/IV/2017 & IM & Carvalho, R. s/n ${ }^{\circ}$ \\
\hline HSTM - Algas 10326 & $11 / \mathrm{V} / 2017$ & IM & Carvalho, R. s/n ${ }^{\circ}$ \\
\hline HSTM - Algas 10327 & $09 / \mathrm{VI} / 2017$ & IM & Carvalho, R. s/n ${ }^{\circ}$ \\
\hline HSTM - Algas 10328 & $04 / \mathrm{X} / 2016$ & $\mathrm{IMe}$ & Carvalho, R. s/n ${ }^{\circ}$ \\
\hline HSTM - Algas 10329 & $10 / \mathrm{II} / 2017$ & $\mathrm{IMe}$ & Carvalho, R. s/n ${ }^{\circ}$ \\
\hline HSTM - Algas 10330 & 09/VII/2016 & $\mathrm{IMe}$ & Carvalho, R. s/n ${ }^{\circ}$ \\
\hline HSTM - Algas 10331 & 06/XII/2016 & $\mathrm{IMe}$ & Carvalho, R. s/n ${ }^{\circ}$ \\
\hline HSTM - Algas 10332 & $17 / \mathrm{XI} / 2016$ & $\mathrm{IMe}$ & Carvalho, R. s/n ${ }^{\circ}$ \\
\hline HSTM - Algas 10333 & 09/IX/2016 & $\mathrm{IMe}$ & Carvalho, R. s/n ${ }^{\circ}$ \\
\hline HSTM - Algas 10334 & 11/VIII/2016 & $\mathrm{IMe}$ & Carvalho, R. s/n ${ }^{\circ}$ \\
\hline HSTM - Algas 10335 & 10/III/2017 & $\mathrm{IMe}$ & Carvalho, R. s/n ${ }^{\circ}$ \\
\hline HSTM - Algas 10336 & 04/I/2017 & $\mathrm{IMe}$ & Carvalho, R. s/n ${ }^{\circ}$ \\
\hline HSTM - Algas 10337 & 07/IV/2017 & $\mathrm{IMe}$ & Carvalho, R. s/n ${ }^{\circ}$ \\
\hline HSTM - Algas 10338 & $11 / \mathrm{V} / 2017$ & $\mathrm{IMe}$ & Carvalho, R. s/n ${ }^{\circ}$ \\
\hline HSTM - Algas 10339 & 09/VI/2017 & $\mathrm{IMe}$ & Carvalho, R. s/n ${ }^{\circ}$ \\
\hline
\end{tabular}




\section{RESULTADOS E DISCUSSÃO}

Um total de 41 táxons de diatomáceas do gênero Pinnularia, incluindo 29 espécies, duas variedades nominais e dez variedades não nominais, foi registrado pelo presente estudo no lago Verde. A descrição dos táxons e as ilustrações dos mesmos são apresentados a seguir.

Pinnularia acuminata var. novaezealandica Krammer, Diatoms of Europe. v. 1, p. 159, pl. 148, figs. 1-5. 2000.

(Figs. 2, 3)

Valvas lineares, margens paralelas levemente convexas na região mediana, extremidades cuneado-arredondadas. Área axial larga alcançando 1/2 da largura da valva, área central assimétrica com fáscia transversal estreita. Rafe ligeiramente lateral com extremidades proximais curvadas $\mathrm{e}$ extremidades distais em forma de gancho. Estrias paralelas, ligeiramente radiadas na região mediana e levemente convergentes nas extremidades valvares.

Morfometria: compr. 66,5-90,9 $\mu \mathrm{m}$; larg. 11,8-14,7 $\mu \mathrm{m}$; estrias $10-11 / 10 \mu \mathrm{m}$.

Material examinado: HSTM - Algas 10318, 10330, 10305, 10292, 10309, 10298, 10322, 10333, 10304, 10296, 10332, 10307, 10331, 10308, 10324, 10336, 10311, 10299, 10329, 10306, 10335, 10337, 10313, 10326.

Comentário: os espécimes observados assemelham-se morfologicamente ao material tipo de Krammer (2000), encontrado na Nova Zelândia em registro fóssil, contudo apresentam diferenças na largura $(14,7-16 \mu \mathrm{m})$ e maior densidade de estrias $(9-10 / 10 \mu \mathrm{m})$. Observando a ilustração de Tremarin et al. (2010) para o Rio Guaraguaçu, $P$. acuminata var. novaezealandica difere pelas dimensões valvares (compr. 86,1-133,3 $\mu \mathrm{m}$; larg. 13,3-14,1 $\mu \mathrm{m}$ ).

Pinnularia amazonica Metzeltin \& Krammer, Iconographia Diatomologica, v. 5, p. 163, pl. 176, figs. 4-7. 1998.

(Figs. 4, 5)

Valvas lineares, margens trionduladas, levemente infladas na região mediana, extremidades subcapitadoarredondadas. Área axial estreita alcançando 1/3 a 1/4 da largura da valva, área central rômbica com fáscia transversal larga. Rafe lateral com extremidades proximais curvadas e extremidades distais em forma de gancho. Estrias radiadas na região mediana e levemente convergentes em direção as extremidades valvares.

Morfometria: compr. 81,1-107,3 $\mu \mathrm{m}$; larg. 10,6-12 $\mu \mathrm{m}$; estrias $10-11 / 10 \mu \mathrm{m}$.

Material examinado: HSTM - Algas 10321, 10298, 10322, 10333, 10296, 10332, 10307, 10294, 10308, 10336, 10306, 10312, 10300, 10326, 10303.

Comentário: as dimensões e características morfológicas apresentaram semelhança com as ilustrações e descrição original em Metzeltin \& Lange-Bertalot (1998), diferindo um pouco em relação aos espécimes registrados no curso superior da bacia do Rio Negro por Pereira et al. (2017) (compr. 79-100 $\mu \mathrm{m}$; larg. 11,4-13 $\mu \mathrm{m}$; estrias 9-11/10 $\mu \mathrm{m}$ ).

Pinnularia amoena Hustedt, Internationale Revue der gesamten Hydrobiologie. 50(3): 391-410. p. 399, fig. 31. 1965.

(Figs. 6, 57- 60)

Em MEV (Figs. 57-60), visualiza-se padrão de alvéolos com 3-6 fileiras de aréolas arredondadas, cada fileira com 27-28 aréolas em $5 \mu \mathrm{m}$.

Morfometria: compr. 107,3-140,6 $\mu \mathrm{m}$; larg. 16,1-19,1 $\mu \mathrm{m}$; estrias $10 / 10 \mu \mathrm{m}$.

Material examinado: HSTM - Algas 10318, 10330, 10305, 10292, 10334, 10309, 10298, 10322, 10333, 10310, 10319, 10328, 10304, 10296, 10320, 10332, 10307, 10294, 10317, 10331, 10308, 10295, 10324, 10336, 10311, 10299, 10316, $10329,10306,10293,10323,10335,10312,10300,10325$, 10313, 10326, 10338, 10314, 10302, 10303.

Comentário: exemplares observados neste estudo apresentaram amplitude maior de dimensões valvares quando comparado com o observado por Hustedt (1965) (compr. 100-125 $\mu \mathrm{m}$; larg. 15-17 $\mu \mathrm{m}$ ), em material oriundo da região de Santarém e Belterra. No entanto, considerando que parte dos indivíduos examinados estiveram dentro do intervalo de variação métrica registrada por aquele autor e, considerando que as características morfológicas se assemelham com a descrição e com a ilustração apresentadas por Hustedt (1965) concluímos tratar-se da mesma espécie.

Pinnularia aquaenigrae Krammer \& Metzeltin, Iconographia Diatomologica, v. 18, p. 192, pl. 259, figs. 3-6. 2007.

(Fig. 7)

Valvas lineares, margens paralelas, extremidades arredondadas. Área axial estreita alcançando $1 / 5$ a $1 / 4$ da largura da valva, área central rômbica ligeiramente assimétrica com fáscia transversal estreita e curta. Rafe ligeiramente lateral com extremidades proximais curvadas e extremidades distais em forma de gancho. Estrias radiadas a paralelas na região mediana e levemente convergentes em direção às extremidades valvares.

Morfometria: compr. 87,3-99,3 $\mu \mathrm{m}$; larg. 12,8-14,9 $\mu \mathrm{m}$; estrias 10-11/10 $\mu \mathrm{m}$.

Material examinado: HSTM - Algas 10330, 10292, 10334, 10298, 10322, 10333, 10319, 10328, 10304, 10296, 10332, 10294, 10317, 10331, 10308, 10295, 10324, 10311, 10299, 10329, 10306, 10335, 10312, 10300, 10313, 10338, 10314, 10302, 10339, 10315.

Comentário: alguns espécimes analisados apresentaram maiores dimensões valvares que o descrito originalmente (compr. 57-93 $\mu \mathrm{m}$; larg. 12,7-14 $\mu \mathrm{m}$ ) em Metzeltin \& Lange-Bertalot (2007), no entanto foram semelhantes morfologicamente e em densidade de estrias. Recentemente 
a espécie foi registrada no rio Negro por Pereira et al. (2017).

Pinnularia boyeriformis Krammer \& Metzeltin, Iconographia Diatomologica, v. 5, p. 165, pl. 184, figs. 4-6. 1998.

(Fig. 8)

Valvas lineares, margens paralelas, infladas na região mediana, extremidades arredondadas. Área axial estreita alcançando $1 / 5$ da largura da valva, área central ligeiramente rômbica com fáscia transversal larga. Rafe lateral com extremidades proximais curvadas e extremidades distais em forma de gancho. Estrias radiadas na região mediana e convergentes em direção às extremidades valvares.

Morfometria: compr. 84,8-100,5 $\mu \mathrm{m}$; larg. 13,1-14 $\mu \mathrm{m}$; estrias 9-11/10 $\mu \mathrm{m}$.

Material examinado: HSTM - Algas 10330, 10305, 10292 , 10298, 10310, 10296, 10332, 10307, 10294, 10317, 10308, 10336, 10329, 10335, 10312.

Comentário: os espécimes apresentaram dimensões valvares menores que as do material tipo descrito em Metzeltin \& Lange-Bertalot (1998) para o rio Negro (compr. 100-121 $\mu \mathrm{m}$; larg. 14,7-16 $\mu \mathrm{m}$ ), no entanto, apresentam valores de comprimento valvar similares aos registrados por Pereira et al. (2017) que constataram valores de comprimento valvar entre $82,6-85 \mu \mathrm{m}$. Os indivíduos analisados apresentam valvas menos infladas na região mediana, podendo esta característica corresponder a uma variabilidade morfológica da espécie.
Pinnularia confirma Metzeltin \& Krammer, Iconographia Diatomologica, v. 5, p. 166, pl. 180, figs. 11-13. 1998.

(Fig. 9)

Valvas lineares, margens paralelas, extremidades arredondadas. Área axial larga alcançando 1/2 da largura da valva, área central ausente. Rafe lateral com extremidades proximais curvadas e extremidades distais em forma de gancho. Estrias levemente radiadas na região mediana e paralelas nas extremidades valvares.

Morfometria: compr. 74,9 $\mu \mathrm{m}$; larg. 9,29 $\mu \mathrm{m}$; estrias $13 / 10 \mu \mathrm{m}$.

Material examinado: HSTM - Algas 10309.

Comentário: no presente estudo foi observado apenas um exemplar da espécie, este apresenta semelhança com a descrição e ilustração do material tipo. Pereira et al. $(2012,2017)$ registraram a espécie como frequente em diferentes ambientes na bacia do rio Negro, sendo observados indivíduos com menores dimensões valvares (compr. 46-64 $\mu \mathrm{m}$ e larg. 6,6-9,4 $\mu \mathrm{m}$ ).

Pinnularia discrepantia Metzeltin \& Krammer, Iconographia Diatomologica. v.5. p.169, pl 191, figs. 1-2. 1998.

(Figs. 10, 11, 61-63)

Em MEV (Figs. 61-63), observa-se que internamente as fissuras terminais da rafe apresentam helictoglossa proeminente e alvéolos com 3-4 fileiras de aréolas arredondadas.

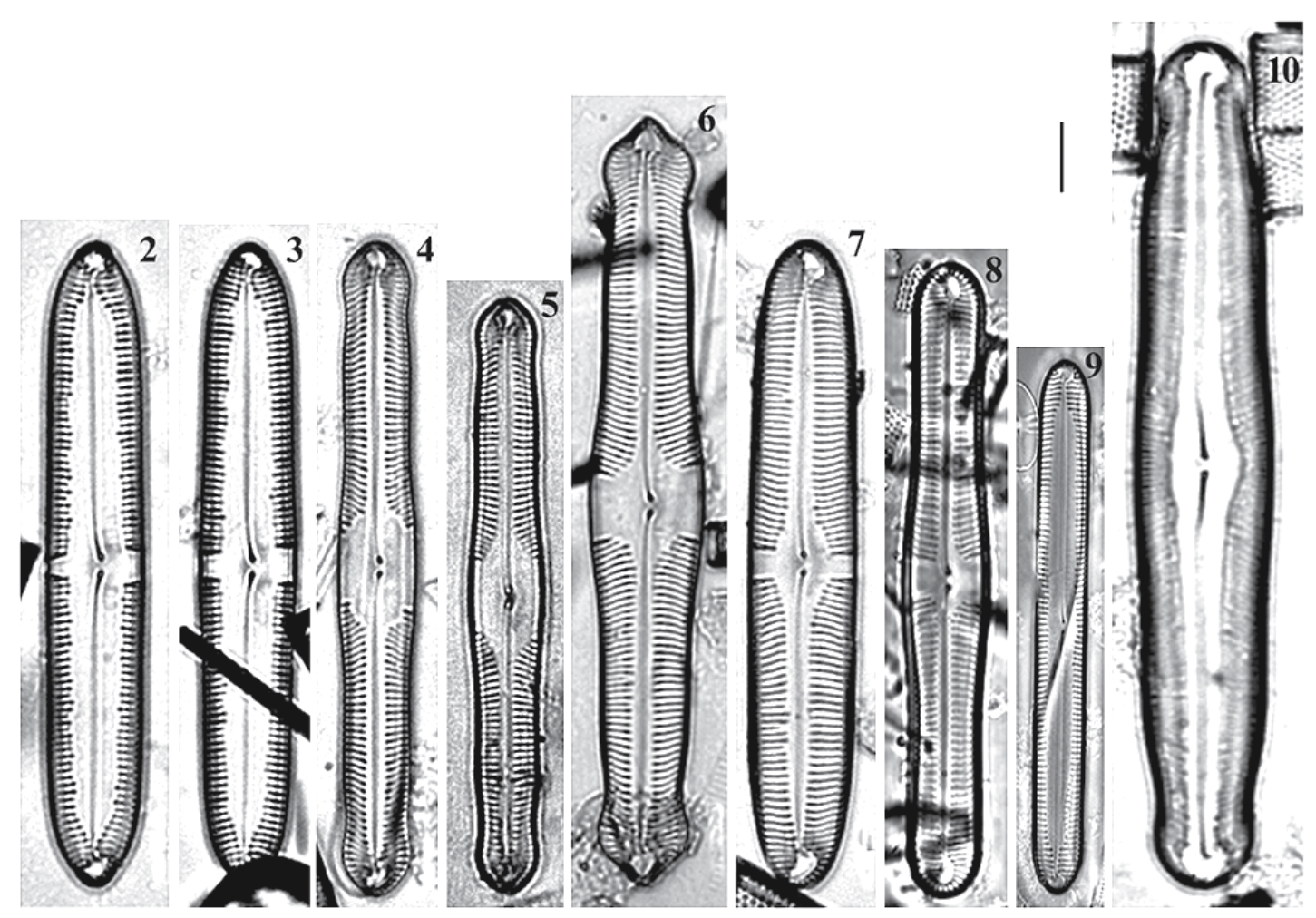

Figs. 2-10. Imagens em MO. 2, 3. Pinnularia acuminata var. novaezealandica; 4, 5. P. amazônica; 6. P. amoena; 7. P. aquaenigrae; 8. P. boyeriformis; 9. P. confirma; 10. P. discrepantia. Barra $=10 \mu \mathrm{m}$. 
Morfometria: compr. 97,1-139,2 $\mu \mathrm{m}$; larg. 16,5-20,4 $\mu \mathrm{m}$; estrias 12-13/10 $\mu \mathrm{m}$.

Material examinado: HSTM - Algas 10318, 10330, 10305, 10292, 10321, 10334, 10298, 10322, 10310, 10297, 10319, 10296, 10320, 10332, 10307, 10317, 10331, 10308, 10324, 10336, 10311, 10299, 10306, 10335, 10326, 10302, 10327.

Comentário: alguns espécimes analisados apresentaram dimensões e densidade de estrias menores que as do material tipo descrito em Metzeltin \& Lange-Bertalot (1998) (compr. 105-197 $\mu \mathrm{m}$; larg. 18,5-26 $\mu \mathrm{m}$; estrias 1316/10), no entanto assemelham-se à descrição morfológica e ilustrações da espécie. A espécie foi registrada por Pereira et al. (2013) para o lago Tupé na bacia do rio Negro com densidade de estrias $(15 / 10 \mu \mathrm{m})$ superior ao registrado no presente estudo.

Pinnularia divergens var. malayensis Hustedt, Internationale Revue der gesamten Hydrobiologie 42: 82, fig. 159. 1942.

(Figs. 12, 13)

Valvas lineares, margens paralelas levemente trionduladas, infladas na região mediana, extremidades amplamente arredondadas. Área axial estreita alcançando $1 / 5$ a 1/3 da largura da valva, área central rômbica com fascia transversal estreita. Rafe complexa com extremidades proximais ligeiramente curvadas e extremidades distais em forma de gancho. Estrias radiadas na região mediana e convergentes em direção às extremidades valvares.

Morfometria: compr. 111,2-141,5 $\mu \mathrm{m}$; larg. 25,3-30,9 $\mu \mathrm{m}$; estrias 8-9/10 $\mu \mathrm{m}$.

Material examinado: HSTM - Algas 10292, 10321, 10298, 10333, 10310, 10319, 10304, 10296, 10320, 10294, 10317,
10295, 10324, 10336, 10306, 10293, 10323, 10312, 10326, 10339.

Comentário: os exemplares observados assemelham-se morfologicamente aos registrados no lago Tupé e no rio Negro por Pereira et al. $(2013,2017)$ diferindo por alguns espécimes que apresentaram menor comprimento e maior largura que os descritos pelos autores (compr. 137,4-170 $\mu \mathrm{m}$; larg. 25,2-28,2 $\mu \mathrm{m}$ e compr. 116-118 $\mu \mathrm{m}$; larg. 28-28,3 $\mu \mathrm{m}$, respectivamente).

Pinnularia divergens var. media Krammer, Diatoms of Europe. v. 1:61, 215, pl. 34: figs. 1-5. 2000.

(Figs. 14,15, 64-67)

Valvas linear-lanceoladas, margens paralelas a levemente onduladas, extremidades capitada-arredondadas. Área axial estreita alcançando 1/5 a 1/4 da largura da valva, área central rômbica e assimétrica com fáscia transversal muito estreita. Rafe lateral com extremidades proximais levemente curvadas e extremidades distais em forma de baioneta, internamente as fissuras terminais apresentam helictoglossa proeminente (Figs. 65, 67). Estrias radiadas na região mediana e convergentes em direção às extremidades valvares. Padrão de alvéolos com 3-5 fileiras de aréolas arredondadas, cada fileira com 6-8 aréolas em $1 \mu \mathrm{m}$.

Morfometria: compr. 60,8-82,4 $\mu \mathrm{m}$; larg. 11,3-14,9 $\mu \mathrm{m}$; estrias 10-12/10 $\mu \mathrm{m}$.

Material examinado: HSTM - Algas 10318, 10330, 10305, 10292, 10321, 10334, 10309, 10298, 10322, 10333, 10310, 10297, 10319, 10328, 10304, 10296, 10320, 10332, 10307, 10294, 10317, 10331, 10308, 10295, 10324, 10336, 10311, $10299,10316,10329,10306,10293,10323,10335,10312$, $10300,10325,10337,10313,10326,10338,10314,10302$, $10327,10315,10303$.

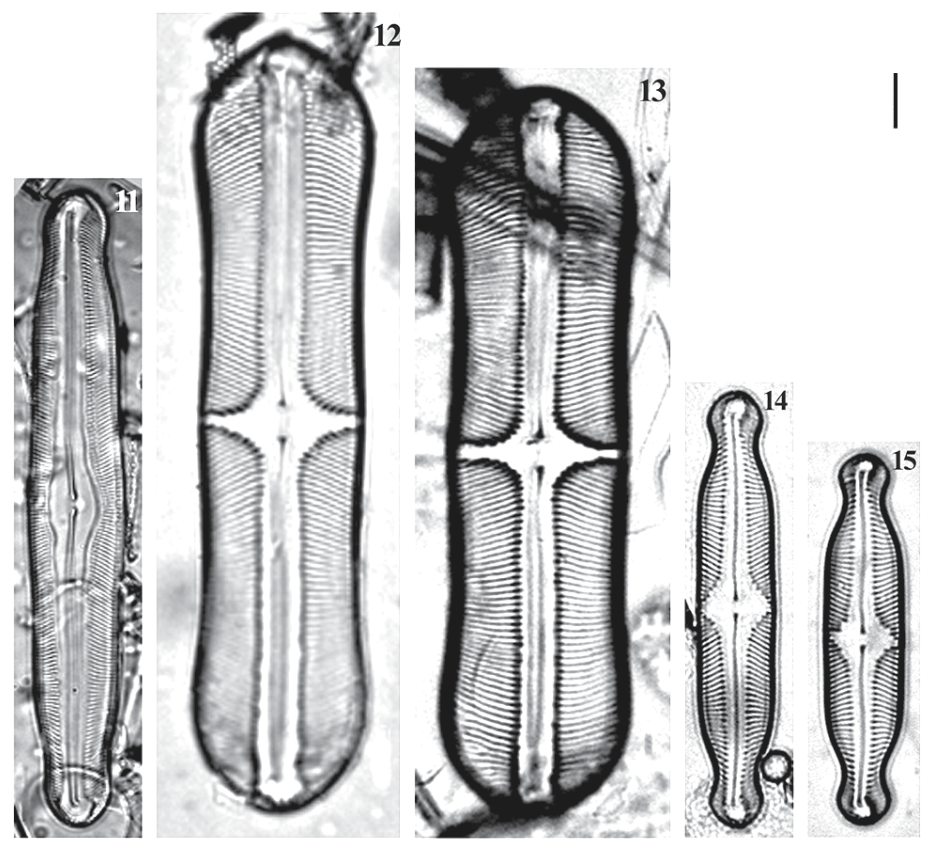

Figs. 11-15. Imagens em MO. 11. Pinnularia discrepantia; 12, 13. P. divergens var. malayensis; 14, 15. P. divergens var. media. Barra $=10 \mu \mathrm{m}$. 
Comentário: alguns exemplares apresentaram poucas diferenças nas dimensões (compr. 40-70; larg. 10-13) e densidade de estrias $(10-11 / 10 \mu \mathrm{m})$ do material tipo descrito por Krammer (2000).

Pinnularia divergens var. mesoleptiformis Krammer \& Metzeltin, Iconographia Diatomologica, v. 5, p. 170, pl. 173, fig. 1-4. 1998.

(Figs. 16, 17, 68 ,69)

Valvas linear-lanceoladas infladas na região mediana, margens trionduladas, extremidades capitadas. Área axial estreita alcançando $1 / 5$ a 1/3 da largura da valva, área central rômbica com fascia transversal estreita. Rafe lateral com extremidades proximais levemente curvadas e extremidades distais em forma de gancho, internamente as fissuras terminais apresentam helictoglossa proeminente (Figs. $68,69)$. Estrias radiadas na região mediana a convergentes em direção às extremidades valvares. Padrão de alvéolos com 3-6 fileiras de aréolas arredondadas, cada fileira com 12-14 aréolas em $2 \mu \mathrm{m}$.

Morfometria: compr. 73,4-100,3 $\mu \mathrm{m}$; larg. 12,2-16,1 $\mu \mathrm{m}$; estrias 9-11/10 $\mu \mathrm{m}$.

Material examinado: HSTM - Algas 10318, 10330, 10305, 10298, 10322, 10310, 10308, 10306, 10323, 10325.

Comentário: os espécimes encontrados possuem morfologia semelhante à do material tipo descrito em Metzeltin \& Lange-Bertalot (1998) para o rio Potaro (Guiana), no entanto, os indivíduos registrados na Guiana apresentaram menor intervalo de variação em relação às dimensões valvares (compr. 69-81 $\mu \mathrm{m}$; larg. 13,4 $\mu \mathrm{m}$ ) e densidade de estrias $(9-10 / 10 \mu \mathrm{m})$. Em um estudo para a bacia do Rio Negro, Pereira et al. (2017) identificaram exemplares com maiores dimensões valvares (compr. 72-

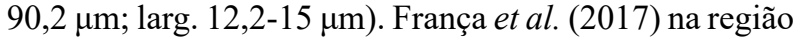
central do Brasil identificaram a espécie com dimensões semelhantes as aqui observadas (compr. 76,71 $\mu \mathrm{m}$; larg. $12,54 \mu \mathrm{m}$; estrias $11 / 10 \mu \mathrm{m}$ ), sendo que estes autores ao fazerem a descrição do táxon o descrevem com rafe complexa, porém Pereira et al. (2017) e Krammer (2000) descrevem como rafe lateral, assim como no presente estudo.

Pinnularia divergens var. rostrata Krammer \& Metzeltin, Iconographia Diatomologica, v. 5, p. 172, pl. 171, figs. 5. 1998.

(Figs. 18, 19)

Morfometria: compr. 83,1-108,3 $\mu \mathrm{m}$; larg. 19,2-21,5 $\mu \mathrm{m}$; estrias $8-9 / 10 \mu \mathrm{m}$.

Material examinado: HSTM - Algas 10330, 10305, 10321, 10309, 10322, 10333, 10310, 10304, 10332, 10307, 10294, 10331, 10308, 10311, 10299, 10312, 10338, 10302.

Comentário: a descrição original da variedade foi feita a partir de um único exemplar em material oriundo do rio Tapajós (Metzeltin \& Lange-Bertalot, 1998), que apresentou dimensões valvares semelhantes às observadas no presente estudo (compr. $104 \mu \mathrm{m}$; larg. $21 \mu \mathrm{m}$ ). Segundo Metzeltin e Lange-Bertalot (1998), esta variedade é semelhante a $P$. divergens var. divergens $\mathrm{W}$.Smith diferindo pelas extremidades rostradas, e as estrias mais grosseiras $(8 / 10 \mu \mathrm{m}$ contra $10-12 / 10 \mu \mathrm{m})$. Analisando a descrição morfológica e as ilustrações acreditamos que os exemplares encontrados no presente estudo pertençam a $P$. divergens var. rostrata.

Pinnularia divergens var. subcuneata Krammer \& Metzeltin, Iconographia Diatomologica, v. 5, p. 172, pl. 171, figs. 2-4. 1998.

(Fig. 20)

Morfometria: compr. 64,4-91,3 $\mu \mathrm{m}$; larg. 13,3-15,5 $\mu \mathrm{m}$; estrias 9-11/10 $\mu \mathrm{m}$.

Material examinado: HSTM - Algas 10296, 10307, 10335, 10300, 10337, 10339.

Comentário: os espécimes encontrados assemelhamse morfologicamente ao material tipo, coletado no rio Tapajós, descrito em Metzeltin \& Lange-Bertalot (1998). Alguns indivíduos, no entanto, apresentaram dimensões ligeiramente maiores quando comparado com o material tipo (compr. 60-86 $\mu \mathrm{m}$; larg. 12-13,4 $\mu \mathrm{m}$ ) e, também, apresentaram uma variação na densidade de estrias, enquanto o material tipo apresentou um número constante $(10 / 10 \mu \mathrm{m})$.

Pinnularia diversarea Krammer \& Metzeltin, Iconographia Diatomologica, v. 5, p. 173, pl. 174, fig. 2-5. 1998.

(Fig. 21)

Morfometria: compr. 67,1-84,7 $\mu \mathrm{m}$; larg. 15-17,1 $\mu \mathrm{m}$; estrias $9-10 / 10 \mu \mathrm{m}$.

Material examinado: HSTM - Algas 10330, 10334, 10309, 10333, 10310, 10319, 10304, 10296, HSTM - Algas 10332, 10294, 10317, 10331, 10308, 10295, 10324, 10336, 10311, 10329, 10306, 10293, 10335, 10312, 10300, 10315.

Comentário: $P$. diversarea é descrita originalmente para o lago Calado (Metzeltin \& Lange-Bertalot 1998) sendo comparada à $P$. divergens var. ignorata Krammer e P. legumiformis Krammer, das quais se diferencia pelo contorno valvar e formato da área central. Os espécimes examinados apresentaram características morfológicas e a densidade de estrias de acordo com as observadas no material tipo. Por outro lado, o material deste estudo apresentou dimensões um pouco superior ao registrado para a espécie tipo (compr. 65-69 $\mu \mathrm{m}$; larg. 15-16 $\mu \mathrm{m}$ ). Recentemente a espécie foi citada com menor comprimento (compr. 62,8 $\mu \mathrm{m}$ ) no rio Negro por Pereira et al. (2017).

Pinnularia flama (Schmidt) Cleve, Kongliga Svenska Vetenskaps Akademiens Handlingar. 27(3): 1-219, 4 pls. p.89. 1895.

(Fig. 22) 


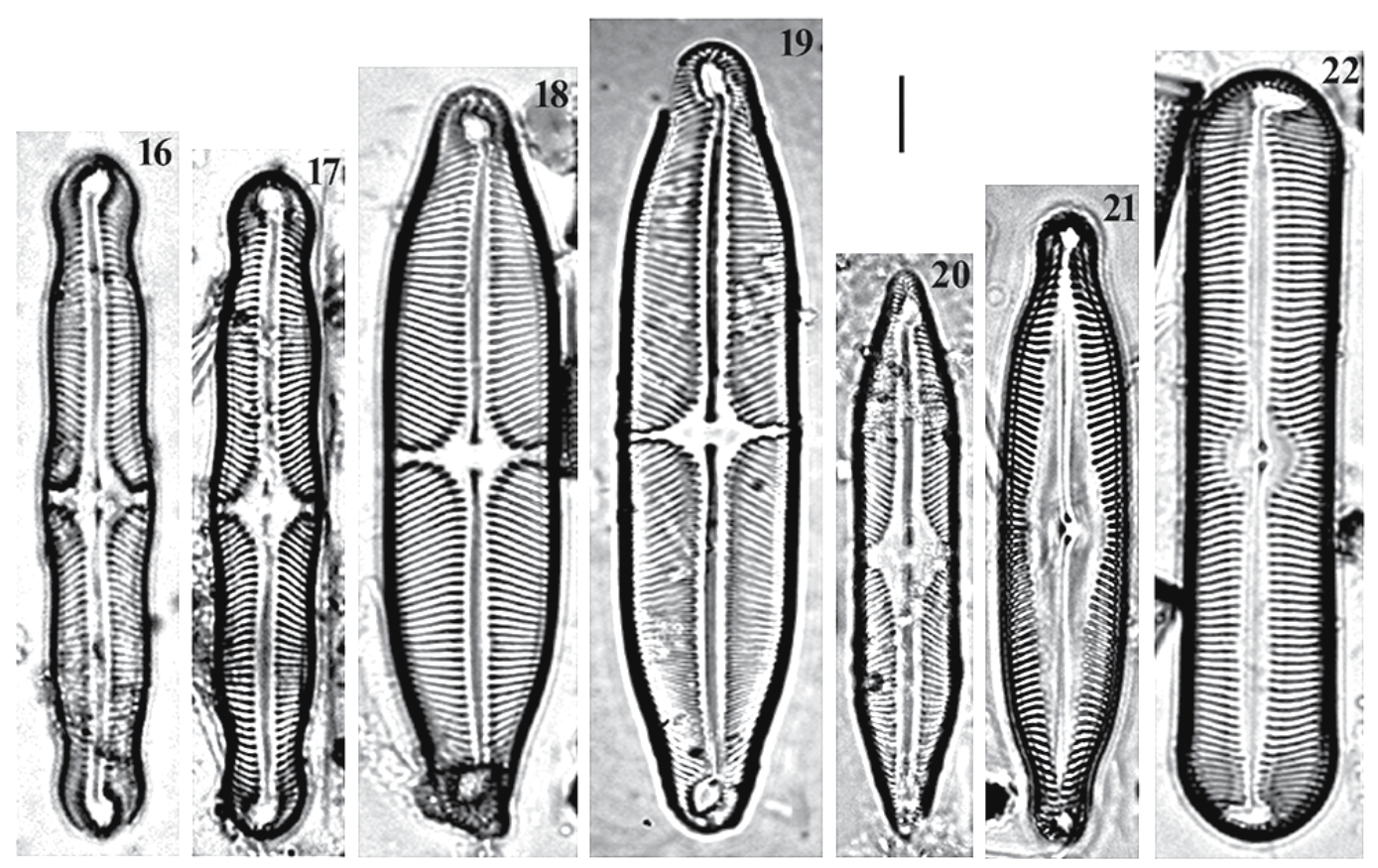

Figs. 16-22. Imagens em MO. 16, 17. Pinnularia divergens var. mesoleptiformis; 18, 19. P. divergens var. rostrata; 20. P. divergens var. subcuneata; 21. . diversarea; 22. P. flamma. Barra $=10 \mu \mathrm{m}$.

Morfometria: compr. 78,7-98,8 $\mu \mathrm{m}$; larg. 16,5-17,1 $\mu \mathrm{m}$; estrias 8-9/10 $\mu \mathrm{m}$.

Material examinado: HSTM - Algas 10305, 10292, 10334, 10298, 10322, 10304, 10296, 10294, 10308, 10312.

Comentário: os exemplares observados apresentam menores dimensões valvares e maior densidade de estrias do que os descritos originalmente para a espécie (compr. 125$160 \mu \mathrm{m}$; larg. $18,30 \mu \mathrm{m}$; estrias $6-7,5 / 10 \mu \mathrm{m}$ ), porém, suas características morfológicas são semelhantes às descritas e ilustradas na descrição original, assim consideramos tratar-se de P. flamma.

Pinnularia graciloides var. rumrichae Krammer, Diatoms of Europe. v. 1, p. 128, pl. 99: figs 4. 2000.

(Figs. 23, 24)

Valvas trionduladas, extremidades capitadas. Área axial estreita alcançando $1 / 4$ a $1 / 3$ da largura da valva, área central rômbica com fáscia transversal larga. Rafe lateral levemente ondulada com extremidades proximais curvadas e extremidades distais em forma de baioneta. Estrias radiadas na região mediana e convergentes em direção às extremidades valvares.

Morfometria: compr. 65,0-74,6 $\mu \mathrm{m}$, larg. 7,7-8,9 $\mu \mathrm{m}$; estrias 11-12/10 $\mu \mathrm{m}$.

Material examinado: HSTM - Algas 10305, 10292, 10334, 10298, 10322, 10319, 10304, 10331, 10306.

Comentário: a espécie encontrada neste estudo assemelhase nas características morfológicas e nas dimensões valvares às da descrição original de Krammer (2000), em material proveniente do Chile. Os exemplares são semelhantes às espécies Pinnularia perumbrosa (Metzeltin \& Krammer)
Metzeltin \& Lange-Bertalot e Pinnularia subumbrosa Metzeltin \& Krammer, diferindo destas pelo formato valvar fortemente triondulado e região mediana muito inflada nestes táxons.

Pinnularia hemipteriformis Krammer \& Metzeltin, Iconographia Diatomologica, v. 5, p. 177, pl. 174, figs. 6, 7. 1998.

(Fig. 25)

Morfometria: compr. 46,4-63,3 $\mu \mathrm{m}$; larg. 8,2-8,9 $\mu \mathrm{m}$; estrias $11-12 / 10 \mu \mathrm{m}$.

Material examinado: HSTM - Algas 10318, 10330, 10305, 10292, 10321, 10334, 10309, 10298, 10322, 10333, 10310, 10297, 10319, 10328, 10304, 10296, 10320, 10332, 10307, 10294, 10317, 10331, 10308, 10295, 10324, 10336, 10311, 10299, 10316, 10329, 10306, 10335, 10312, 10300, 10325, 10337, 10313, 10326, 10338, 10314, 10302, 10339, 10315.

Comentário: alguns espécimes registrados apresentaram dimensões e densidade de estrias diferentes das observadas no material tipo proveniente do rio Potaro na Guiana (compr. 51-55 $\mu \mathrm{m}$; larg. 9,4 $\mu \mathrm{m}$; estrias $11 / 10 \mu \mathrm{m}$ ), no entanto as características morfológicas conferem com as descritas. Os espécimes são semelhantes à $P$. instabiliformis Krammer \& Metzeltin e a $P$. angustivalva Krammer \& Metzeltin, mas diferem da primeira espécie por apresentar fáscia transversal mais larga e pelo formato e dimensões valvares, sendo que $P$. instabiliformis foi descrita com comprimento entre 36-52 $\mu \mathrm{m}$ e largura entre 10,4-11,7 $\mu \mathrm{m}$ (Metzeltin \& Lange-Bertalot 1998) e, de P. angustivalva em razão desta apresentar maior densidade de estrias (13$14 / 10 \mu \mathrm{m})$, e área axial mais estreita (1/3 da largura da valva), segundo a descrição original da espécie. 
Pinnularia hyalina Hustedt, Atlas der Diatomaceen-kunde. p.385-392, pl. 392, fig. 17-18. 1934.

(Fig. 26)

Valvas linear-lanceoladas, levemente infladas na região mediana, extremidades amplamente arredondadas. Área axial larga alcançando $1 / 3$ da largura da valva, área central rômbica com fáscia transversal estreita. Rafe lateral com extremidades proximais curvadas e extremidades distais em forma de gancho. Estrias radiadas na região mediana e convergentes em direção às extremidades valvares.

Morfometria: compr. 163,4-164,1 $\mu \mathrm{m}$; larg. 17,2-19,4 $\mu \mathrm{m}$; estrias 7-8/10 $\mu \mathrm{m}$.

Material examinado: HSTM - Algas 10318, 10338.

Comentário: os exemplares observados assemelham-se ao material identificado no lago Calado por Metzeltin \& Lange-Bertalot (1998). A espécie foi registrada na bacia do rio Iguaçu por Brassac \& Ludwig (2006), com os seguintes dados morfométricos: comprimento $116 \mu \mathrm{m}$; largura 15 $\mu \mathrm{m}$; estrias 9-10/10, dimensões que diferem dos indivíduos registrados no presente estudo.

Pinnularia instabiliformis Krammer \& Metzeltin, Iconographia Diatomologica, v. 5, p. 177, pl. 174, figs. 8-12. 1998.

(Fig. 27)

Valvas lineares, margens convexas, extremidades cuneado-arredondadas. Área axial larga alcançando 1/2 da largura da valva, área central com fáscia transversal larga. Rafe lateral com extremidades proximais curvadas e extremidades distais em forma de gancho. Estrias levemente radiadas na região mediana e convergentes em direção as extremidades valvares.

Morfometria: compr. 40,6-51,6 $\mu \mathrm{m}$; larg. 9,1-9,4 $\mu \mathrm{m}$; estrias $12 / 10 \mu \mathrm{m}$.

Material examinado: HSTM - Algas 10330, 10305, 10298, 10319.

Comentário: os exemplares apresentaram características morfológicas semelhantes às do material tipo, diferindo, no entanto, por apresentarem menores valores de largura valvar e menor densidade de estrias, tendo o material tipo apresentado largura valvar entre 10,4-11,7 $\mu \mathrm{m}$ e densidade de estrias de $11 / 10 \mu \mathrm{m}$.

Pinnularia instabilis (Schmidt) Metzeltin, Iconographia Diatomologica, v. 5, p. 178, pl. 194, figs. 1-3; pl. 205, figs. 4-5. 1998.

(Figs. 28, 70-72)

Valvas elípticas-lanceoladas, margens paralelas, extremidades apiculadas. Área axial larga alcançando $1 / 3$ a $1 / 2$ da largura da valva, área central simétrica. Rafe filiforme com extremidades proximais curvadas e extremidades distais em forma de gancho. Estrias paralelas a levemente radiadas ao longo da valva. Padrão de alvéolos com 5-7 fileiras de aréolas arredondadas, cada fileira com 14-15 aréolas em $2 \mu \mathrm{m}$ (Figs. 70-72).
Morfometria: compr. 57,3-120,8 $\mu \mathrm{m}$; larg. 18,1-23,9 $\mu \mathrm{m}$; estrias $10-11 / 10 \mu \mathrm{m}$.

Material examinado: HSTM - Algas 10318, 10330, 10305, 10292, 10334, 10309, 10298, 10322, 10333, 10310, 10319, 10328, 10304, 10296, 10320, 10332, 10307, 10294, 10317 , 10331, 10308, 10295, 10324, 10336, 10311, 10299, 10329, 10306, 10293, 10323, 10335, 10312, 10300, 10325, 10337, 10326, 10338, 10314, 10302.

Comentário: os indivíduos registrados possuem uma amplitude de variação de comprimento e largura maior do que foi registrado por Metzeltin \& Lange-Bertalot (1998) (compr. 69-91 $\mu \mathrm{m}$; larg. 21-23 $\mu \mathrm{m}$; estrias 9-10/10 $\mu \mathrm{m}$ ). No entanto, as características morfológicas dos exemplares analisados neste estudo conferem com a descrição e ilustrações da publicação de Metzeltin \& Lange-Bertalot (1998), inclusive com a presença de espessamento ondulado ao longo da área axial. Pereira et al. (2013) registraram indivíduos da espécie para o lago Tupé com menores dimensões valvares e maior densidade de estrias que as descritas originalmente (compr. 61-85 $\mu \mathrm{m}$; larg. 17-20 $\mu \mathrm{m}$; estrias 10-12/10 $\mu \mathrm{m}$ ). Recentemente, Pereira et al. (2017) em estudo nos cursos superior e médio do rio Negro observaram indivíduos com maior comprimento valvar (compr. 77,6-100 $\mu \mathrm{m}$ ).

Pinnularia liyanlingae Metzeltin \& Lange-Bertalot, Iconographia Diatomologica, v. 18, p. 207, pl. 238, figs. 1-4; pl. 239, figs. 1-3. 2007.

(Fig. 29)

Valvas lineares, margens ligeiramente tri-onduladas e infladas na região mediana, extremidades cuneadaarredondadas. Área axial larga alcançando 1/3 a 1/2 da largura da valva, área central assimétrica, ligeiramente circular. Rafe semi-complexa com extremidades proximais curvadas e extremidades distais em forma de gancho. Estrias levemente radiadas na região mediana, levemente paralelas e convergentes em direção as extremidades valvares.

Morfometria: compr. 86,8-219,8 $\mu \mathrm{m}$; larg. 22,4-31,6 $\mu \mathrm{m}$; estrias 7-9/10 $\mu \mathrm{m}$.

Material examinado: HSTM - Algas 10318, 10330, 10305, 10292, 10309, 10298, 10322, 10333, 10310, 10319, 10328, 10296, 10331, 10295, 10336, 10299, 10329, 10335.

Comentário: alguns espécimes apresentam pequena diferença no comprimento valvar $(94-200 \mu \mathrm{m}) \mathrm{em}$ comparação com a descrição do material tipo para o lago Calado que apresentou comprimento entre 94-200 $\mu \mathrm{m}$ (Metzeltin \& Lange-Bertalot 2007). Recentemente, no plâncton de ambientes de águas pretas, Pereira et al. (2013; 2017) registraram indivíduos com densidade de estrias $(8-9 / 10 \mu \mathrm{m})$, o que se encaixa no intervalo de valores registrados no presente estudo.

Pinnularia manausensis Pereira \& Torgan, Phytotaxa, v. 158 , n. 2, p. 159, figs. 2-6, 22-25. 2014

(Figs. 30, 73-75) 


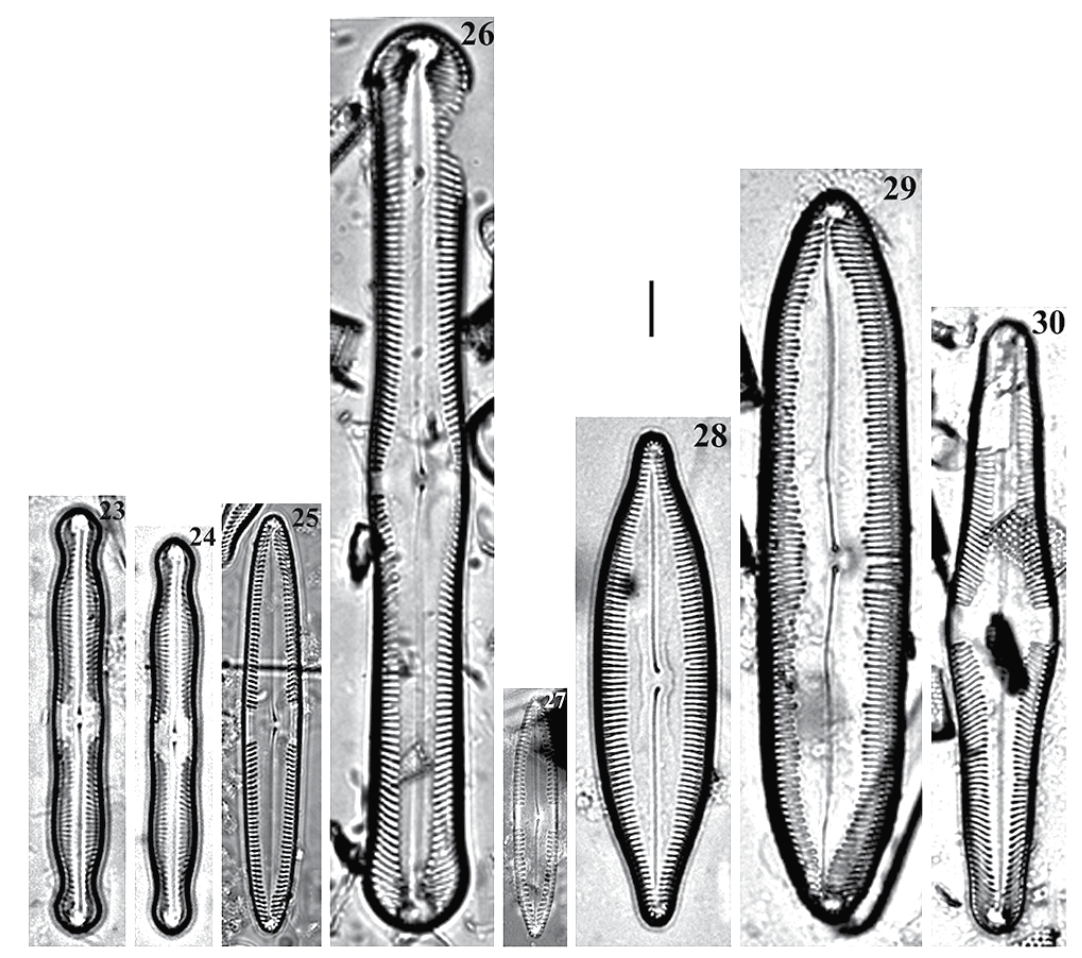

Figs. 23-30. Imagens em MO. 23, 24. Pinnularia graciloides var. rumrichae; 25. P. hemipteriformis; 26. P. hyalina; 27. P. instabiliformis; 28. $P$. instabilis; 29. P. liyanlingae; 30. P. manausensis. Barra $=10 \mu \mathrm{m}$.

Valvas linear-lanceoladas, margens paralelas levemente trionduladas, extremidades subcapitadas. Área axial estreita alcançando $1 / 3$ da largura da valva, área central rômbica com fascia transversal larga. Rafe lateral com extremidades proximais curvadas e extremidades distais em forma de gancho, internamente as fissuras terminais apresentam helictoglossa proeminente (Fig. 75). Estrias radiadas na região mediana e convergentes em direção às extremidades valvares. Padrão de alvéolos com 3-7 fileiras de aréolas arredondadas, cada fileira com 7-8 aréolas em $1 \mu \mathrm{m}$.

Morfometria: compr. 109,6-135,3 $\mu \mathrm{m}$; larg. 18,8-20,4 $\mu \mathrm{m}$; estrias $9 / 10 \mu \mathrm{m}$.

Material examinado: HSTM - Algas 10330, 10304, 10307, 10294, 10311.

Comentário: os exemplares estudados apresentam dimensões e densidade de estrias em $10 \mu \mathrm{m}$ diferentes das registradas no material tipo proveniente do lago Tupé (compr. 121-130,2 $\mu \mathrm{m}$; larg. 15,5-18,5 $\mu \mathrm{m}$; estrias 10-11/10 $\mu \mathrm{m})$ descrito em Pereira et al. (2014), mas assemelham-se à descrição morfológica e às ilustrações do referido estudo.

Pinnularia meridiana var. concava Metzeltin \& Krammer, Iconographia Diatomologica, v. 5, p. 180, pl. 181, figs. 6,7. 1998.

(Figs. 31, 76, 77)

Valvas lineares, margens trionduladas, extremidades arredondadas. Área axial estreita alcançando 1/7 a 1/5 da largura da valva, área central rômbica com fáscia transversal larga. Rafe filiforme com extremidades proximais ligeiramente curvadas e extremidades distais em forma de gancho, internamente as fissuras terminais apresentam helictoglossa proeminente (Fig. 77). Estrias radiadas na região mediana e convergentes em direção às extremidades valvares. Padrão de alvéolos com 3-6 fileiras de aréolas arredondadas, cada fileira com 12-14 aréolas em $2 \mu \mathrm{m}$.

Morfometria: compr. 49,4-82,0 $\mu \mathrm{m}$; larg. 10,8-12,4 $\mu \mathrm{m}$; estrias $10-12 / 10 \mu \mathrm{m}$.

Material examinado: HSTM - Algas 10330, 10305, 10292, 10321, 10309, 10298, 10322, 10333, 10328, 10304, 10296, 10307, 10294, 10317, 10331, 10308, 10336, 10311, 10299 , 10329, 10306, 10293, 10335, 10312, 10300, 10313, 10326, 10303.

Comentário: os exemplares observados apresentaram dimensões e densidade de estrias diferentes do material tipo descrito por Metzeltin \& Lange-Bertalot (1998) na região Amazônica que registraram comprimento entre 61-63 $\mu \mathrm{m}$, largura entre 12,5-12,7 $\mu \mathrm{m}$ e, 10 estrias em $10 \mu \mathrm{m}$. Esta espécie foi registrada com dimensões e densidade de estrias diferentes das originais por Pereira et al, $(2012,2013,2017)$ na bacia do rio Negro, sendo que as dimensões registradas no presente estudo condizem com as apresentadas por estes autores que registraram variações de 51 a $67 \mu \mathrm{m}$ de comprimento, 11 a $12 \mu \mathrm{m}$ de largura e de 10-13 estrias em $10 \mu \mathrm{m}$.

Pinnularia microstauron (Ehrenberg) Cleve, Acta Societatia pro Fauna et Flora Fennica, v. 8, n. 2, p. 28. 1891.

(Fig. 32) 
Morfometria: compr. 60,0-82,4 $\mu \mathrm{m}$; larg. 11,6-12,3 $\mu \mathrm{m}$; estrias $9-10 / 10 \mu \mathrm{m}$.

Material examinado: HSTM - Algas 10318, 10330, 10296, 10320, 10317, 10312, 10338.

Comentário: os espécimes registrados se assemelham às ilustrações apresentadas por Metzeltin \& Lange-Bertalot (2007) na prancha 263, figuras 7-10 encontradas no lago Jurucuí, estado do Pará. Pereira et al. (2017) registraram a ocorrência da espécie nos cursos superior e médio do rio Negro com menor dimensão valvar (compr. 45-50 $\mu \mathrm{m}$; larg. 9,5-10 $\mu \mathrm{m}$ ), sendo possível verificar através das figuras $4 \mathrm{~N}$ e $5 \mathrm{~A}$ do referido estudo extremidades muito rostradas e não rostrado-arredondadas, como no presente estudo.

Pinnularia mollenhaueri Metzeltin \& Lange-Bertalot, Iconographia Diatomologica v. 18. p. 210, pl. 244, figs. 4-7. 2007.

(Fig. 33)

Valvas elípticas, margens paralelas, extremidades cuneada-arredondadas. Área axial larga alcançando 1/2 da largura da valva, área central simétrica. Rafe ligeiramente lateral com extremidades proximais levemente curvadas e extremidades distais em forma de gancho. Estrias curtas, paralelas e levemente radiadas nas extremidades valvares.

Morfometria: compr. 60,9 $\mu \mathrm{m}$; larg. 14,3 $\mu \mathrm{m}$; estrias $12 / 10 \mu \mathrm{m}$.

Material examinado: HSTM - Algas 10322, 10307, 10336, 10311, 10329.

Comentário: o exemplar observado assemelha-se ao material tipo descrito para o rio Negro em Metzeltin \& Lange-Bertalot (2007). O espécime é similar a P. acuminata W. Smith pelo formato valvar, diferindo pelas extremidades e pela conformação e densidade de estrias $(8-10 / 10 \mu \mathrm{m})$. P. perinstabilis Metzeltin \& Krammer difere do exemplar estudado pelas extremidades fortemente cuneadas, e menor densidade de estrias em $10 \mu \mathrm{m}(8 / 10 \mu \mathrm{m})$.

Pinnularia monicae Metzeltin \& Lange-Bertalot, Iconographia Diatomologica, v. 18:211, pl. 246, figs. 1-5. 2007.

(Figs. 34, 78-80)

Em MEV (Figs. 78-80), observa-se internamente as fissuras terminais da rafe apresentam helictoglossa proeminente. Alvéolos com 3-5 fileiras de aréolas arredondadas.

Morfometria: compr. 78,4-116,7 $\mu \mathrm{m}$; larg. 13,4-17,8 $\mu \mathrm{m}$; estrias $9 / 10 \mu \mathrm{m}$.

Material examinado: HSTM - Algas 10318, 10330, 10305, 10292, 10321, 10334, 10309, 10298, 10322, 10333, 10310, 10297, 10319, 10328, 10304, 10296, 10320, 10332, 10307, 10294, 10317, 10331, 10308, 10295, 10324, 10336, 10311, $10299,10316,10329,10306,10293,10323,10335,10312$, 10300, 10325, 10313, 10326, 10338, 10314, 10302, 10327 , 10339.
Comentário: os espécimes observados possuem semelhanças na morfologia e dimensões com os descritos para o lago Jurucuí (Metzeltin \& Lange-Bertalot 2007) e com as descrições e ilustrações de Pereira et al. (2013, 2017) em estudos na bacia do rio Negro.

Pinnularia parallela var. parallela Brun, Le Diatomiste, 2: pls. 14-17, 19-20. pl. 14, fig. 7. 1895.

(Fig. 35)

Valvas lineares, margens paralelas, extremidades amplamente arredondadas. Área axial estreita alcançando 1/5 da largura da valva, área central arredondada. Rafe lateral com extremidades proximais curvadas e extremidades distais em forma de gancho. Estrias radiadas na região mediana e paralelas a convergentes em direção às extremidades valvares.

Morfometria: compr. 135,1 $\mu \mathrm{m}$; larg. 16,4 $\mu \mathrm{m}$; estrias $11 / 10 \mu \mathrm{m}$.

Material examinado: HSTM - Algas 10298, 10320.

Comentário: o exemplar observado apresenta similaridade com P. spitsbergensis ilustrada por Cleve (1894-1895), entretanto difere pelas estrias paralelas, rafe filiforme e extremidades distais da rafe em formato de baioneta.

Pinnularia percuneata var. percuneata Krammer, Diatoms of Europe 1: 232, Pl. 139, figs 1-7. 2000.

(Fig. 36)

Valvas lineares, margens paralelas, extremidades cuneada-arredondadas. Área axial estreita alcançando $1 / 4$ a $1 / 3$ da largura da valva, área central ligeiramente arredondada. Rafe lateral-semicomplexa com extremidades proximais curvadas e extremidades distais em forma de gancho. Estrias radiadas na região mediana e paralelas a levemente convergentes em direção às extremidades valvares.

Morfometria: compr. 101,8-134,5 $\mu \mathrm{m}$; larg. 16,1-18,4 $\mu \mathrm{m}$; estrias 8-9/10 $\mu \mathrm{m}$.

Material examinado: HSTM - Algas 10330, 10305, 10292, 10334, 10299, 10325.

Comentário: os exemplares observados conferem com a morfologia do material tipo descrito por Krammer (2000) apresentando indivíduos com comprimento valvar um pouco maior do apresentado no intervalo de variação do material tipo que foi de 63-130 $\mu \mathrm{m}$. A espécie difere de $P$. viridis (Nitzsch) Ehrenberg e de $P$. viridiformes Krammer pelos ápices arredondados e área axial mais estreita em $P$. viridis e pelos ápices fortemente cuneados e área axial mais estreita em $P$. viridiformes.

Pinnularia perinstabilis Metzeltin \& Krammer, Iconographia Diatomologica, v. 5, p. 183, pl. 193, figs. 1-3. 1998.

(Fig. 37) 


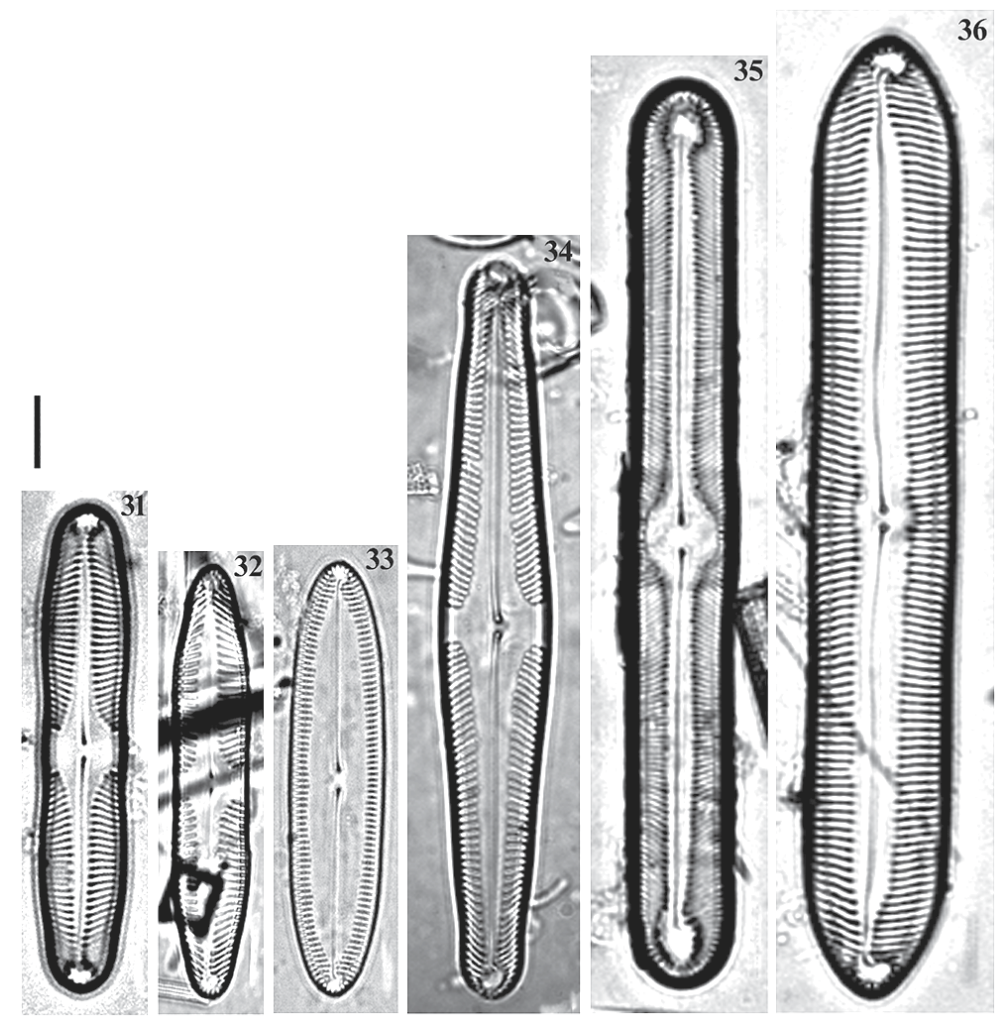

Figs. 31-36. Imagens em MO. 31. Pinnularia meridiana var. concava; 32. P. microstauron; 33. P. mollenhaueri; 34. P. monicae; 35. P. parallela var. parallela; 36. . percuneata var. percuneata. Barra $=10 \mu \mathrm{m}$.

Morfometria: compr. 60,7-86,6 $\mu \mathrm{m}$; larg. 22,4-24,2 $\mu \mathrm{m}$; estrias $9 / 10 \mu \mathrm{m}$.

Material examinado: HSTM - Algas 10305, 10334, 10328, $10296,10307,10331,10308,10336,10311,10329,10306$, 10335, 10312, 10300, 10338, 10314.

Comentário: as características métricas e morfológicas dos espécimes estudados são semelhantes às do material do rio Arapiuns (Metzeltin \& Lange-Bertalot 1998), diferindo apenas por apresentar densidade de estrias, $9 / 10 \mu \mathrm{m}$, ligeiramente maior do registrado no material tipo, que foi de $8 / 10 \mu \mathrm{m}$. A espécie foi recentemente registrada no rio Negro por Pereira et al. (2017), sendo que alguns indivíduos apresentaram maior comprimento (compr. 60-101,1 $\mu \mathrm{m}$ ) e maior densidade de estrias em $10 \mu \mathrm{m}(9-12 / 10 \mu \mathrm{m})$ do que as descritas originalmente (compr. 68-95 $\mu \mathrm{m}$; larg. 23,8$28,8 \mu \mathrm{m}$; estrias $8 / 10 \mu \mathrm{m}$ ). As ilustrações dos espécimes apresentadas pelos autores são similares àqueles por nós registrados, com exceção de um exemplar ilustrado (figura $5 \mathrm{M})$ do referido artigo no qual o espécime possui leve constrição na região mediana.

Pinnularia pogoii Scherer, Diatom Research, 3(1): 152, figs. 56-60, 70, 71. 1988.

(Figs. 38, 39)

Valvas elípticas a lanceoladas, margens paralelas, extremidades cuneado-arredondadas. Área axial larga alcançando $1 / 4$ da largura da valva, área central com fáscia transversal larga. Rafe lateral com extremidades proximais curvadas e extremidades distais em forma de gancho. Estrias paralelas a ligeiramente radiadas na região mediana da valva.

Morfometria: compr. 14,9-18,2 $\mu \mathrm{m}$; larg. 5,3-5,5 $\mu \mathrm{m}$; estrias $7 / 10 \mu \mathrm{m}$.

Material examinado: HSTM - Algas 10309, 10332.

Comentário: esta espécie foi registrada na bacia amazônica em ambientes de águas pretas como o lago Tupé e o rio Negro, tendo apresentado valores de comprimento entre 13 e $19,6 \mu \mathrm{m}$, largura entre 5,0 e $5,7 \mu \mathrm{m}$ e densidade de estrias entre 6 e $8 \mathrm{em} 10 \mu \mathrm{m}$ (Pereira et al. 2013, 2017), intervalos de valores aos quais os indivíduos registrados no presente estudo se encaixam.

Pinnularia polyonca (Brébisson) W.Smith, A synopsis of the British Diatomaceae, v. 2:95. 1856.

(Fig. 40)

Valvas lineares, margens trionduladas, infladas na região mediana, extremidades capitadas. Área axial estreita alcançando 1/4 da largura da valva, área central rômbica com fáscia transversal larga. Rafe lateral com extremidades proximais curvadas e extremidades distais em forma de gancho. Estrias radiadas na região mediana e convergentes em direção às extremidades valvares.

Morfometria: compr. 99,9 $\mu \mathrm{m}$; larg. 12,8 $\mu \mathrm{m}$; estrias $11 / 10 \mu \mathrm{m}$.

Material examinado: HSTM - Algas 10294. 
Comentário: o exemplar registrado apresenta maior comprimento e largura do que aqueles analisados por Krammer (2000), que apresentaram comprimento entre 50-90 $\mu \mathrm{m}$ e largura entre $8-12 \mu \mathrm{m}$, por outro lado mostrou semelhança em relação à densidade de estrias e características morfológicas. Recentemente, a espécie foi registrada no curso superior e médio do rio Negro (Pereira et al. 2017), com características similares àquelas por nós registradas, incluindo as dimensões valvares (compr. 52,8107,5 $\mu \mathrm{m}$; larg. 8-15 $\mu \mathrm{m}$; estrias 10-12/10 $\mu \mathrm{m}$ ).

Pinnularia procera Metzeltin \& Krammer, Iconographia Diatomologica, v. 5, p. 184, pl. 178, figs. 7-11. 1998.

\section{(Fig. 41)}

Morfometria: compr. 69,7 $\mu \mathrm{m}$; larg. $6,8 \mu \mathrm{m}$; estrias $12 / 10$ $\mu \mathrm{m}$.

Material examinado: HSTM - Algas 10309.

Comentário: o exemplar estudado apresenta dimensões e densidade de estrias menores que as apontadas na descrição do material tipo proveniente do rio Tapajós, próximo a Santarém, que apresentou comprimento entre $72-82 \mu \mathrm{m}$; largura entre 8-8,5 $\mu \mathrm{m}$ e, estrias 10-11/10 $\mu \mathrm{m}$ (Metzeltin \& Lange-Bertalot, 1998). No entanto, as características morfológicas conferem com a descrição e ilustrações originais.

Pinnularia rostratissima var. ventricosa Metzeltin \& Lange-Bertalot, Iconographia Diatomologica, v. 5:186, pl. 169, figs. 1-5. 1998.

(Figs. 42, 81, 82)
Valvas amplamente lanceoladas, margens paralelas infladas na região mediana, extremidades capitadas. Área axial larga alcançando $1 / 2$ da largura da valva, área central simétrica fusionada a área axial com fáscia transversal larga. Rafe lateral com extremidades proximais curvadas e extremidades distais em forma de gancho, internamente as fissuras terminais apresentam helictoglossa proeminente (Fig. 82). Estrias radiadas na região mediana e convergentes em direção às extremidades valvares. Padrão de alvéolos com 3-5 fileiras de aréolas arredondadas.

Morfometria: compr. 49,9-68,5 $\mu \mathrm{m}$; larg. 12,4-13,3 $\mu \mathrm{m}$; estrias 11-13/10 $\mu \mathrm{m}$.

Material examinado: HSTM - Algas 10318, 10330, 10305, 10292, 10334, 10309, 10298, 10322, 10333, 10297, 10328, 10304, 10296, 10332, 10307, 10294, 10331, 10308, 10295, 10324, 10336, 10311, 10299, 10329, 10306, 10293, 10335, 10312, 10300, 10313, 10314, 10303.

Comentário: alguns indivíduos estudados apresentaram menores dimensões e maior densidade de estrias em comparação aos descritos originalmente por Metzeltin \& Lange-Bertalot (1998) para o rio Essequibo na Guiana (compr. 54-74 $\mu \mathrm{m}$; larg. 14-17,5 $\mu \mathrm{m}$; estrias 11-12/10 $\mu \mathrm{m}$ ), apresentando, no entanto, características morfológicas similares às do material tipo. Os estudos realizados na bacia do rio Negro por Pereira et al. $(2012,2013,2017)$ registraram indivíduos com dimensões diferentes (compr. 51,3-87 $\mu \mathrm{m}$; larg. 10,3-21 $\mu \mathrm{m}$; estrias 11-14/10 $\mu \mathrm{m})$.

Pinnularia sterrenburgii Metzeltin \& Lange-Bertalot, Iconographia Diatomologica, v.18, p. 222, pl. 243, figs. 1-6. 2007.

(Fig. 43)

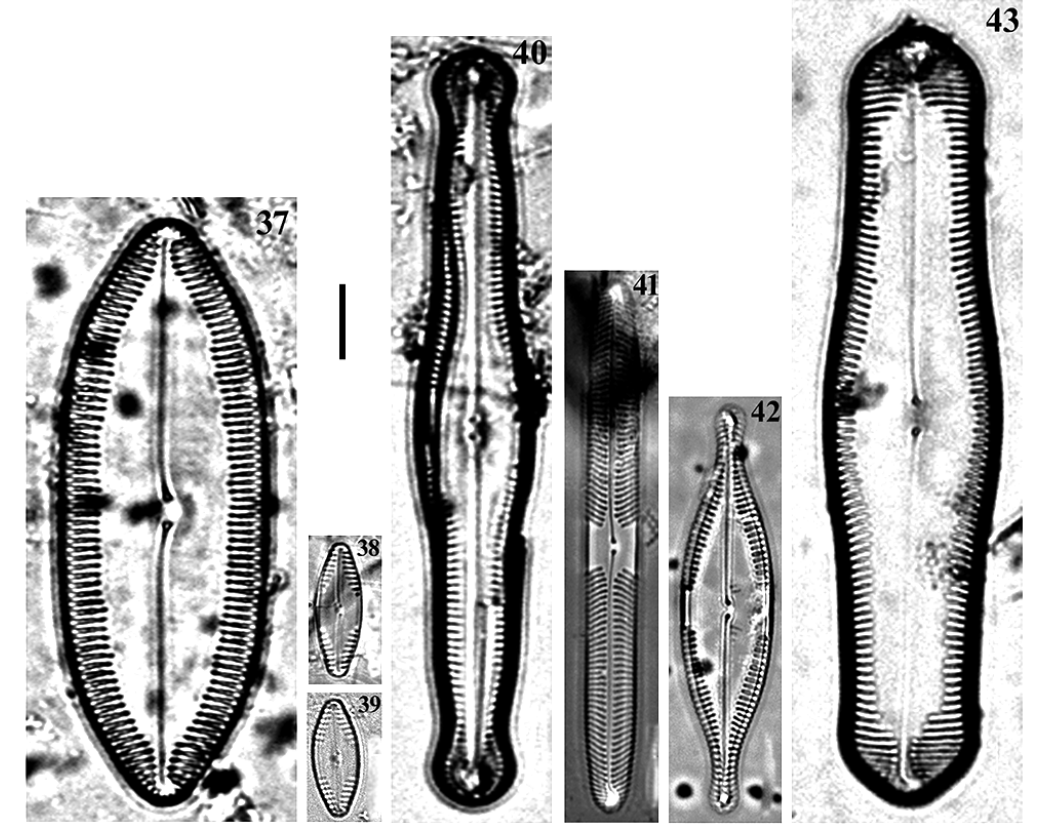

Figs. 37-43. Imagens em MO. 37. Pinnularia perinstabilis; 38, 39. P. pogoii; 40. P.polyonca; 41. P. procera; 42. P. rostratissima var. ventricosa; 43. P.sterrenburgii. Barra $=10 \mu \mathrm{m}$. 
Valvas lineares, margens paralelas, infladas na região mediana, extremidades subcapitado-arredondadas. Área axial larga alcançando aproximadamente $1 / 2$ da largura da valva, área central simétrica. Rafe lateral com extremidades proximais curvadas e extremidades distais em forma de gancho. Estrias radiadas na região mediana e paralelas a levemente convergentes em direção às extremidades valvares.

Morfometria: compr. 86,9-138,9 $\mu \mathrm{m}$; larg. 20,7-26,5 $\mu \mathrm{m}$; estrias 8-10/10 $\mu \mathrm{m}$.

Material examinado: HSTM - Algas 10318, 10330, 10305, 10292, 10321, 10334, 10309, 10298, 10322, 10333, 10310, $10319,10328,10296,10320,10332,10307,10294,10317$, 10331, 10308, 10295, 10324, 10336, 10311, 10299, 10329, 10306, 10293, 10323, 10335, 10312, 10326, 10338, 10302.

Comentário: alguns exemplares estudados apresentaram dimensões menores e maior densidade de estrias que o material tipo descrito para o lago Calado no município de Manacupuru (Metzeltin \& Lange-Bertalot 2007) (compr.

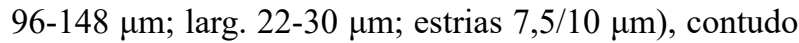
se assemelham à morfologia do material descrito. Esta espécie foi registrada no lago Tupé (Pereira et al. 2013) e no rio Negro (Pereira et al. 2012, 2017), tendo apresentado as seguintes variações morfométricas (compr. 96-145 $\mu \mathrm{m}$; larg. 21-22,6 $\mu \mathrm{m}$; estrias 9-11/10 $\mu \mathrm{m}$ ).

Pinnularia stoermeri Metzeltin \& Lange-Bertalot, Iconographia Diatomologica, v.18, p. 224, pl. 241, figs. 1-3. 2007.

$$
\text { (Figs. 44, 45) }
$$

Morfometria: compr. 100,2-140,1 $\mu \mathrm{m}$; larg. 21,9-29,3 $\mu \mathrm{m}$; estrias 7-8/10 $\mu \mathrm{m}$.

Material examinado: HSTM - Algas 10318, 10330, 10305, 10292, 10309, 10298, 10310, 10328, 10294, 10324, 10299, 10293, 10335, 10312, 10313, 10302.

Comentário: as dimensões e características morfológicas dos indivíduos estudados conferem com aquelas apresentadas na descrição do material tipo proveniente do rio Tapajós próximo a Santarém (Metzeltin \& Lange-Bertalot 2007). A espécie foi registrada no rio Guaraguaçu por Tremarin et al. (2010) com dimensões semelhantes às observadas no presente estudo, mas diferindo ligeiramente por apresentar a região mediana mais fortemente intumescida e ápices não amplamente arredondados, como ilustra a figura 64 do referido estudo.

Pinnularia subboyeri Metzeltin \& Krammer, Iconographia Diatomologica, v. 5, p. 189, pl. 183, figs. 11, 12; pl. 199, fig. 4. 1998.

(Fig. 46)

Valvas linear-lanceoladas, margens paralelas, levemente infladas na região mediana, extremidades cuneadoarredondadas. Área axial estreita alcançando 1/4 a 1/3 da largura da valva, área central rômbica com fáscia transversal estreita. Rafe lateral com extremidades proximais curvadas e extremidades distais em forma de gancho. Estrias radiadas na região mediana e levemente convergente em direção às extremidades valvares.

Morfometria: compr. 125,9-298,0 $\mu \mathrm{m}$; larg. 15,2-18,9 $\mu \mathrm{m}$; estrias $8-9 / 10 \mu \mathrm{m}$.

Material examinado: HSTM - Algas 10318, 10330, 10305, 10321, 10334, 10309, 10322, 10333, 10310, 10297, 10328, 10304, 10296, 10320, 10307, 10294, 10317, 10331, 10308, 10295, 10324, 10336, 10311, 10299, 10316, 10329, 10306, 10293, 10335, 10312, 10300, 10326, 10338, 10314, 10302, 10315.

Comentário: o material analisado no presente estudo possui indivíduos com maiores dimensões valvares e menor densidade de estrias do que o registrado na descrição original da espécie, por outro lado, se assemelha morfologicamente às ilustrações do material tipo e às de outros trabalhos realizados na Amazônia (Pereira et al., 2012, 2013, 2017).

Pinnularia subelongatoides $\mathrm{f}$. linearis (Hustedt) Simonsen. Atlas and catalogue of the diatom types of Friedrich Hustedt. v. 1. p. 493. 1987.

\section{(Figs. 47, 48)}

Morfometria: compr. 90,0-117,3 $\mu \mathrm{m}$; larg. 10,6-12 $\mu \mathrm{m}$; estrias $12 / 10 \mu \mathrm{m}$.

Material examinado: HSTM - Algas 10318, 10330, 10305, 10292, 10321, 10309, 10298, 10322, 10319, 10304, 10320, 10317, 10331, 10316, 10306, 10323, 10335, 10312, 10326, $10338,10339,10315$.

Comentário: as características morfológicas e morfométricas dos exemplares assemelham-se ao material descrito como P. elongatoides $\mathrm{f}$. linearis Hustedt para o lago Jurucuí (Hustedt 1965). O estudo de Pereira et al. (2013) no lago Tupé apresenta a ilustração de um indivíduo (figura 39) que foi identificado como P. superpaulensis, no entanto, após efetuar comparações com os exemplares deste estudo, acreditamos tratar-se de P. subelongatoides pelo fato do indivíduo apresentar margens trionduladas e estrias paralelas na região mediana, o que difere de $P$. superpaulensis que apresenta valvas com margens paralelas e estrias ligeiramente convexas na região mediana.

Pinnularia superpaulensis (Hustedt) Metzeltin \& LangeBertalot, Iconographia Diatomologica, v. 18: 226, pl. 257, figs. 1-3. 2007.

(Figs. 49, 83-85)

Em MEV (Figs. 83-85), visualiza-se que internamente as fissuras terminais da rafe apresentam helictoglossa proeminente, e padrão de alvéolos com 3-7 fileiras de aréolas arredondadas.

Morfometria: compr. 105,6-151,9 $\mu \mathrm{m}$; larg. 13,9-17,1 $\mu \mathrm{m}$; estrias $10-11 / 10 \mu \mathrm{m}$.

Material examinado: HSTM - Algas 10318, 10330, 10292, 10334, 10309, 10298, 10322, 10333, 10310, 10319, 10328, 10296, 10320, 10307, 10294, 10317, 10331, 10308, 10295, 
10324, 10311, 10299, 10316, 10329, 10323, 10335, 10325, 10337, 10313, 10326, 10338, 10314.

Comentário: os espécimes observados são semelhantes morfologicamente aos descritos por Metzeltin \& LangeBertalot (2007) a partir de material oriundo do Lago Jurucuí. No Lago Tupé, Pereira et al. (2013) registraram a espécie citando menores dimensões valvares (compr. 89,3-144 $\mu \mathrm{m}$; larg. 9,2-15,5 $\mu \mathrm{m}$ ) que os observados no corrente estudo. Recentemente, os mesmos autores registraram a espécie nos cursos superior e médio do rio Negro, com comprimento e densidade de estrias semelhantes aos registrados por nós, no entanto, alguns indivíduos apresentaram menor largura valvar (compr. 123-148,3 $\mu \mathrm{m}$; larg. 12,8 -18,3 $\mu \mathrm{m}$; estrias 10-11/10 $\mu \mathrm{m})$ (Pereira et al., 2017).

Pinnularia tumescens Metzeltin \& Krammer, Iconographia Diatomologica, v. 5, p. 193, pl. 186, figs. 1-5. 1998.

(Figs. 50, 51, 86-88)

Valvas lineares, margens ligeiramente trionduladas, extremidades rostrado-subcapitadas. Área axial estreita alcançando $1 / 5$ a $1 / 4$ da largura da valva, área central arredondada. Rafe lateral com extremidades proximais curvadas e extremidades distais em forma de baioneta, internamente as fissuras terminais apresentam helictoglossa proeminente (Fig. 86). Estrias radiadas na região mediana e convergentes em direção às extremidades valvares. Alvéolos com 3-6 fileiras de aréolas arredondadas, cada fileira com 29-31 aréolas em $5 \mu \mathrm{m}$.

Morfometria: compr. 73,1-115,4 $\mu \mathrm{m}$; larg. 12,1-16,3 $\mu \mathrm{m}$; estrias $10-11 / 10 \mu \mathrm{m}$.
Material examinado: HSTM - Algas 10318, 10330, 10305, 10292, 10321, 10334, 10309, 10298, 10322, 10333, 10310, 10297, 10319, 10328, 10304, 10296, 10320, 10332, 10307, 10294, 10317, 10331, 10308, 10295, 10336, 10311, 10299, 10329, 10306, 10293, 10323, 10335, 10312, 10300, 10325, $10337,10313,10326,10338,10314,10302,10327,10339$, $10315,10303$.

Comentário: entre os indivíduos estudados, alguns apresentaram dimensões valvares maiores que as registradas na descrição original do material proveniente do rio Potaro na Guiana (compr. 70-105 $\mu$ m; larg. 12-14 $\mu \mathrm{m}$ ) (Metzeltin \& Lange-Bertalot 1998). Contudo, se assemelham à descrição morfológica e ilustrações do táxon.

Pinnularia tupensis Pereira, Melo \& Torgan, Phytotaxa, v. 158 , n. 2, p. 162 , fig. $13-17,26-32.2014$

(Figs. 52, 53, 89, 90)

Valvas lanceoladas, margens paralelas, extremidades fortemente capitado-arredondadas. Área axial larga alcançando 1/4 da largura da valva, área central rômbica com fáscia transversal larga. Rafe filiforme com extremidades proximais curvadas e extremidades distais não distintas, internamente as fissuras terminais apresentam helictoglossa proeminente (Fig. 89). Estrias radiadas na região mediana e convergentes em direção às extremidades valvares. Padrão de alvéolos com 3-6 fileiras de aréolas arredondadas, cada fileira com 12-13 aréolas em $2 \mu \mathrm{m}$.

Morfometria: compr. 49,9-58,9 $\mu \mathrm{m}$; larg. 10,7-10,8 $\mu \mathrm{m}$; estrias $11 / 10 \mu \mathrm{m}$.

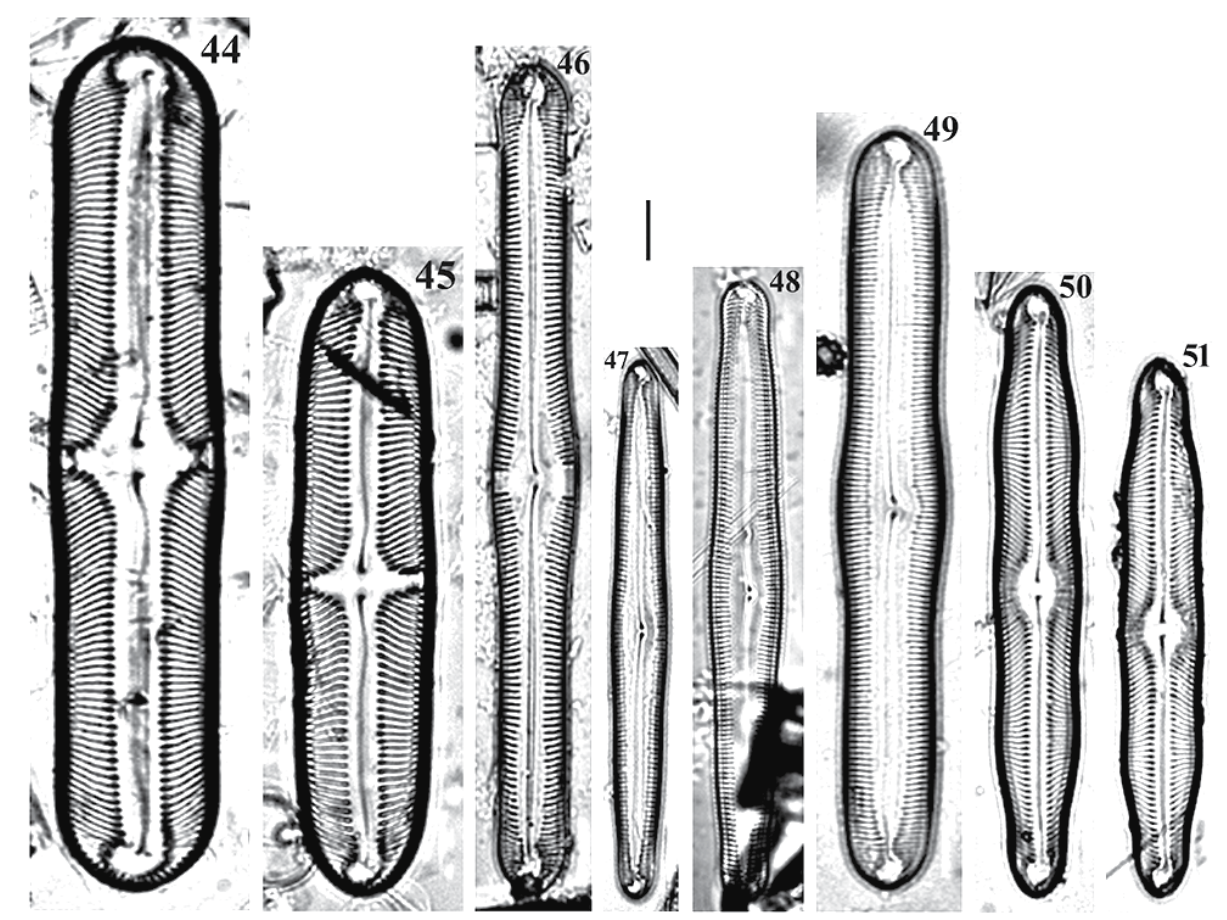

Figs. 44-51. Imagens em MO. 44, 45. Pinnularia stoermeri; 46. P. subboyeri; 47. P. subelongatoides; 48. P. subelongatoides; 49. P. superpaulensis; 50, 51. P. tumescens. Barra $=10 \mu \mathrm{m}$. 
Material examinado: HSTM - Algas 10330, 10292, 10309, 10322, 10333, 10310, 10304, 10307, 10294, 10331, 10308, 10295, 10311, 10299, 10329, 10335, 10313,

10326.

Comentário: o intervalo de variação no comprimento dos exemplares analisados apresentou valores mínimos abaixo do verificado para o material tipo proveniente de amostras do sedimento do lago Tupé, onde foi registrado uma variação entre 52-64,2 $\mu \mathrm{m}$ de comprimento (Pereira et al. 2014), no entanto as características morfológicas são semelhantes à descrição original.

Pinnularia viridiformis Krammer, Bibliotheca Diatomologica, p. 160, pl. 1, fig. 4; pl. 4, figs 1-4; pl. 68, figs 1-4; pl. 69, figs 1-5. 1992.

(Fig. 54)

Valvas lineares, margens paralelas, extremidades cuneado-arredondadas. Área axial estreita alcançando $1 / 5$ a 1/4 da largura da valva, área central ligeiramente arredondada. Rafe complexa com extremidades proximais curvadas e extremidades distais em forma de gancho. Estrias radiadas na região mediana e levemente convergentes em direção às extremidades valvares.

Morfometria: compr. 84,4-159,9 $\mu \mathrm{m}$; larg. 15,3-30,2 $\mu \mathrm{m}$; estrias 7-9/10 $\mu \mathrm{m}$.

Material examinado: HSTM - Algas 10330, 10305, 10292, $10309,10298,10322,10333,10310,10331,10295,10336$, 10329, 10306, 10293, 10312, 10326, 10338, 10314, 10302.

Comentário: alguns exemplares registrados apresentaram maior comprimento e largura que o descrito originalmente

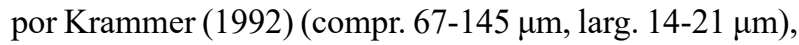
no entanto possuem mesma densidade de estrias e mesma morfologia. Esta espécie foi registrada, também, por Metzeltin \& Lange-Bertalot (2007) para o rio Essequibo na Guiana, e na bacia do Rio Negro por Pereira et al. (2017), quando a espécie foi citada com menores dimensões e maior densidade de estrias (compr. 67,8-91,4 $\mu$ m; larg. 13,5-14,1 $\mu \mathrm{m}$; estrias $11 / 10 \mu \mathrm{m}$ ), além de apresentar extremidades mais arredondadas e estrias aparentemente mais grosseiras.

Pinnularia viridis (Nitzsch) Ehrenberg, Abhandlungen der Königlichen Akademie der Wissenschaften zu Berlin, p. 305 (17), p. 385, pl.1/1: fig.7. 1843.

(Figs. 55, 56)

Valvas elípticas-lanceoladas, margens paralelas, extremidades arredondadas. Área axial larga alcançando $1 / 4$ a $1 / 3$ da largura da valva, área central levemente arredondada. Rafe semi-complexa, extremidades proximais curvadas e extremidades distais em forma de gancho. Estrias $(6-8 / 10 \mu \mathrm{m})$ radiadas na região mediana e convergentes nas extremidades valvares.

Morfometria: compr. 155,9-278,5 $\mu \mathrm{m}$; larg. 28,6-45,9 $\mu \mathrm{m}$; estrias 6-8/10 $\mu \mathrm{m}$.

Material examinado: HSTM - Algas 10318, 10330, 10305, 10321, 10334, 10309, 10322, 10310, 10319, 10304, 10296, 10332, 10307, 10294, 10331, 10308, 10295, 10336, 10299,

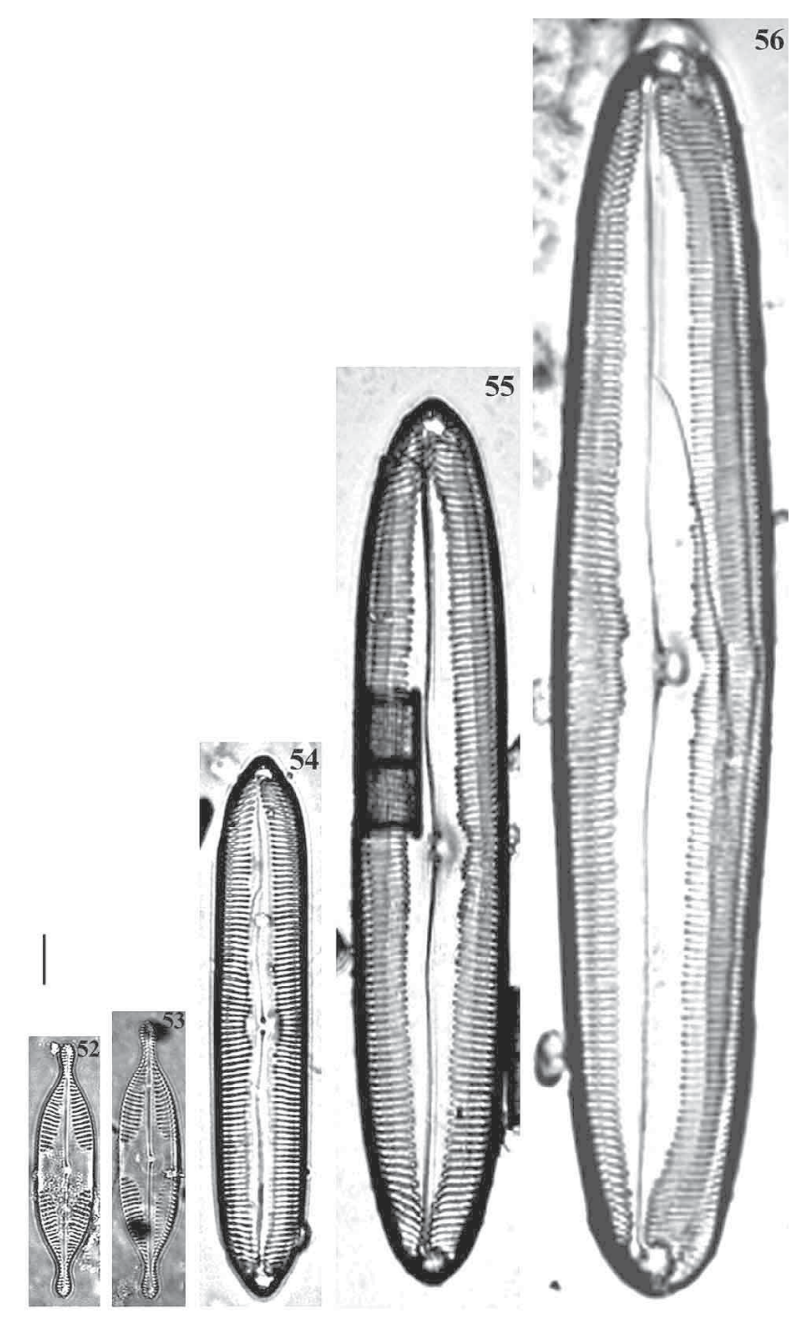

Figs. 52-56. Imagens em MO. 52, 53. P. tupensis; 54. P. viridiformis; 55, 56. . . viridis. Barra $=10 \mu \mathrm{m}$.

$10329,10306,10335,10312,10313,10326,10338,10314$, 10302.

Comentário: entre os espécimes estudados, alguns apresentaram maiores dimensões e maior densidade de estrias que as registradas por Krammer (2000) (compr. 100$182 \mu \mathrm{m}$; larg. 21-30 $\mu \mathrm{m}$; estrias 6-7/10 $\mu \mathrm{m}$ ). Os exemplares observados se assemelham à espécie $P$. vulturis de Metzeltin \& Lange-Bertalot (2007), no entanto diferem pela rafe lateral e pela área axial mais larga.

Entre os táxons registrados no lago Verde, somente dez haviam sido mencionadas anteriormente para ambientes amazônicos de águas claras. Pinnularia amoena, $P$. microstauron, $P$. monicae, $P$. subelongatoides e $P$. superpaulensis foram originalmente descritas por Hustedt (1965) para o lago Jurucuí, localizado na Área de Proteção Ambiental Alter do Chão. As espécies $P$. divergens var. rostrata Krammer \& Metzeltin, $P$. divergens var. subcuneata Krammer \& Metzeltin, P. procera Metzeltin \& Krammer e P. stoermeri Metzeltin \& Lange-Bertalot foram descritas para o rio Tapajós, e a espécie $P$. perinstabilis Metzeltin $\&$ Krammer descrita para o rio Arapiuns, ambas regiões próximas ao município de Santarém. 
Destacamos que mais de $51 \%$ dos táxons registrados no lago Verde constituem primeira citação para o Estado do Pará, a saber: Pinnularia amazonica, $P$. aquaenigrae, $P$. boyeriformis, $P$. confirma, $P$. divergens var. malayensis, $P$. divergens var. mesoleptiformis, $P$. hyalina, P. instabiliformis, $P$. instabilis, $P$. liyanlingae, $P$. manausensis, $P$. meridiana var. concava, $P$. mollenhaueri,
P. pogoii, P. polyonca, P. rostratissima var. ventricosa, $P$. sterrenburgii, $P$. subboyeri, $P$. tupensis, $P$. viridiformis e $P$. viridis. Além disso, cerca de $15 \%, P$. acuminata var. novazealandica, $P$. divergens var. media, $P$. graciloides var. rumrichae, $P$. parallela var. parallela, $P$. percuneata var. percuneata e $P$. tumescens, constituem primeiras citações para a Amazônia brasileira.
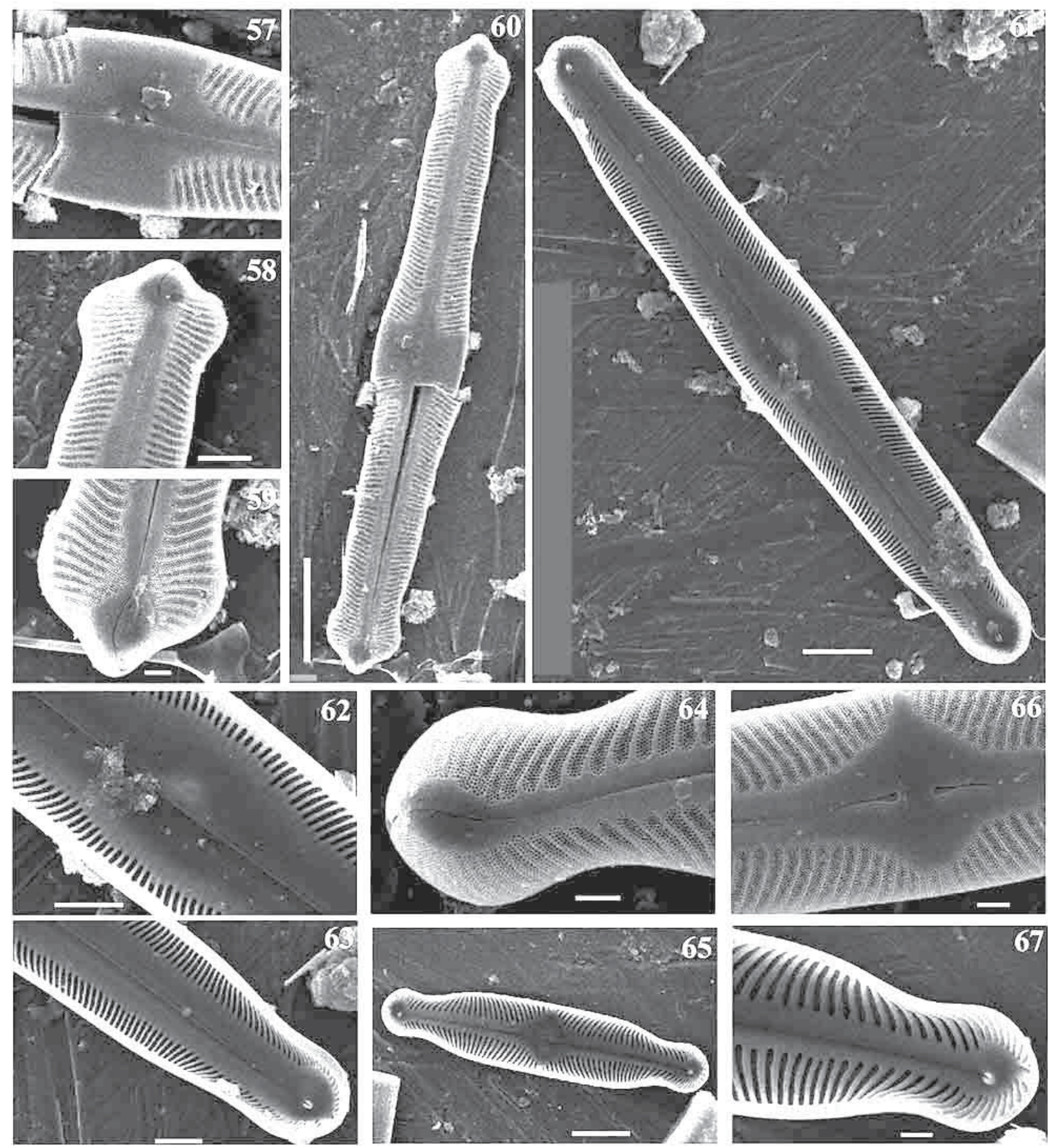

Figs. 57-67. Imagens em MEV. Pinnularia do Lago Verde. 57 - 60. Pinnularia amoena. 57. vista externa das extremidades proximais da rafe na área central; 58, 59. vista externa da extremidade distal da rafe; 60. vista geral externa da valva; 61 - 63. P. discrepantia.61. vista geral interna da valva; 62. vista interna da rafe na área central; 63. vista interna da extremidade distal da rafe; 64 - 67. P. divergens var. media.64. vista externa da extremidade distal da rafe; 65. vista geral interna da valva; 66. vista externa das extremidades proximais da rafe na área central; 67. vista externa da extremidade distal da rafe. Barras: Figs. 57, 58, 62, 63 =5 $\mu$; Figs. 59, 64, 66, $67=2 \mu \mathrm{m}$; Fig. $60=20 \mu \mathrm{m}$; Figs. $61,65=10 \mu \mathrm{m}$. 

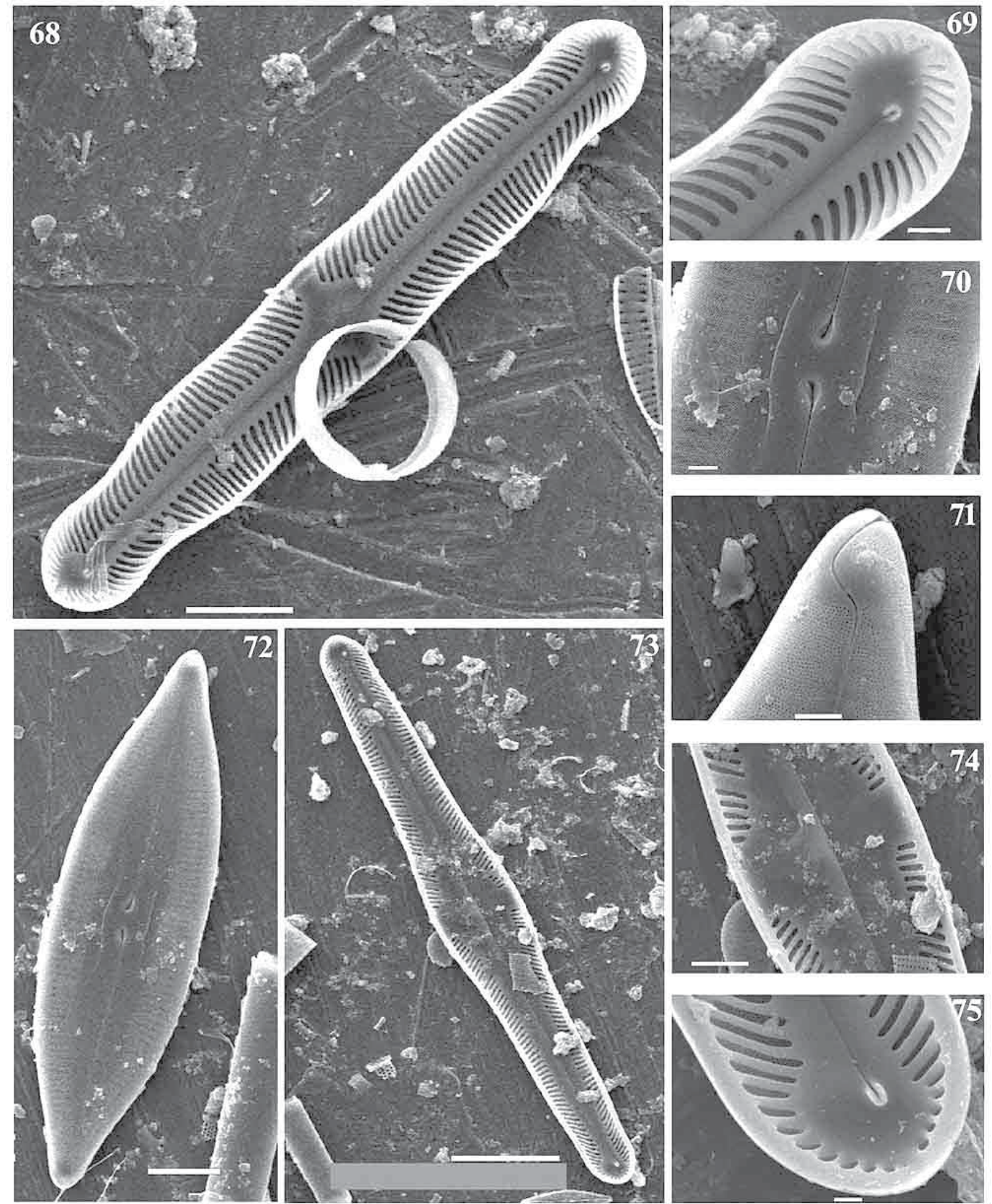

Figs. 68-75. Imagens em MEV. 68, 69. Pinnularia divergens var. mesoleptiformis. 68. vista geral interna da valva; 69. vista interna da extremidade distal da rafe; 70- 72. P. instabilis. 70. vista externa das extremidades proximais da rafe na área central; 71. vista externa da extremidade distal da rafe; 72. vista geral externa da valva; 73 - 75. Imagens em MEV. 73. vista geral interna da valva; 74. vista interna da rafe na área central; 75. vista interna da extremidade distal da rafe. Barras: Figs. 68, $72=10 \mu \mathrm{m}$; Figs. 69, 70, $71=2 \mu \mathrm{m}$; Fig. $73=20 \mu \mathrm{m}$; Fig. $\mathbf{7 4}=5 \mu \mathrm{m} ;$ Fig. $75=1 \mu \mathrm{m}$. 

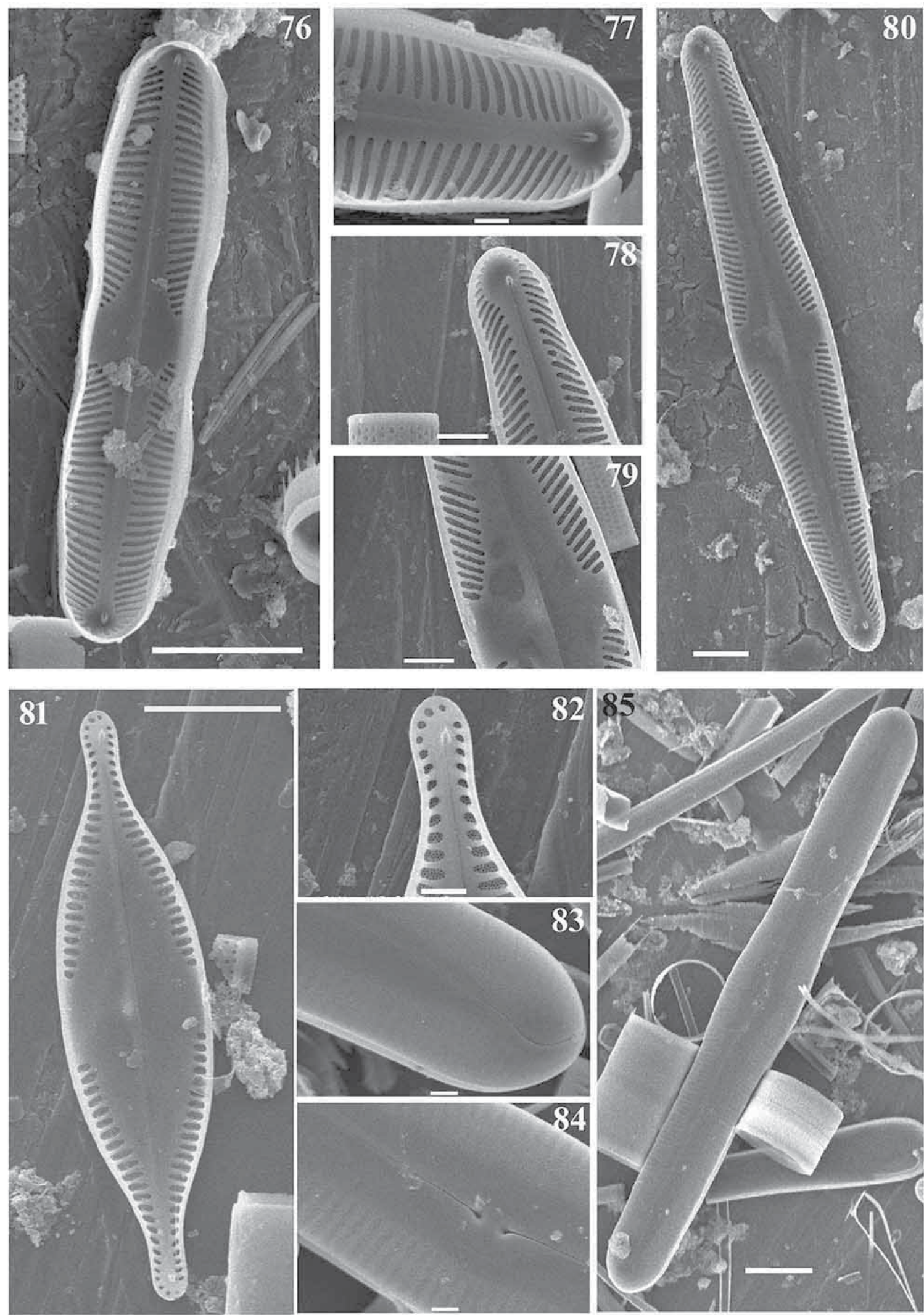

Figs. 76-85. Imagens em MEV. 76, 77. Pinnularia meridiana var. concava. 76. vista geral interna da valva; 77. vista interna da extremidade distal da rafe; 78 - 80. P. monicae. 78. vista interna da extremidade distal da rafe; 79. vista interna da rafe na área central; 80. vista geral interna da valva; 81, 82. P. rostratissima var. ventricosa. 81. vista geral interna da valva; 82. vista interna da extremidade distal da rafe; 83 - 85. P. superpaulensis. 83. vista externa da extremidade distal da rafe; 84. vista externa das extremidades proximais da rafe na área central; $\mathbf{8 5}$. vista geral externa da valva. Barras: Figs. 76, 80, 81, 85 $=10 \mu \mathrm{m}$; Figs. 77, 82, 83, 84 $=2 \mu \mathrm{m}$; Figs. 78, 79 $=5 \mu \mathrm{m}$. 

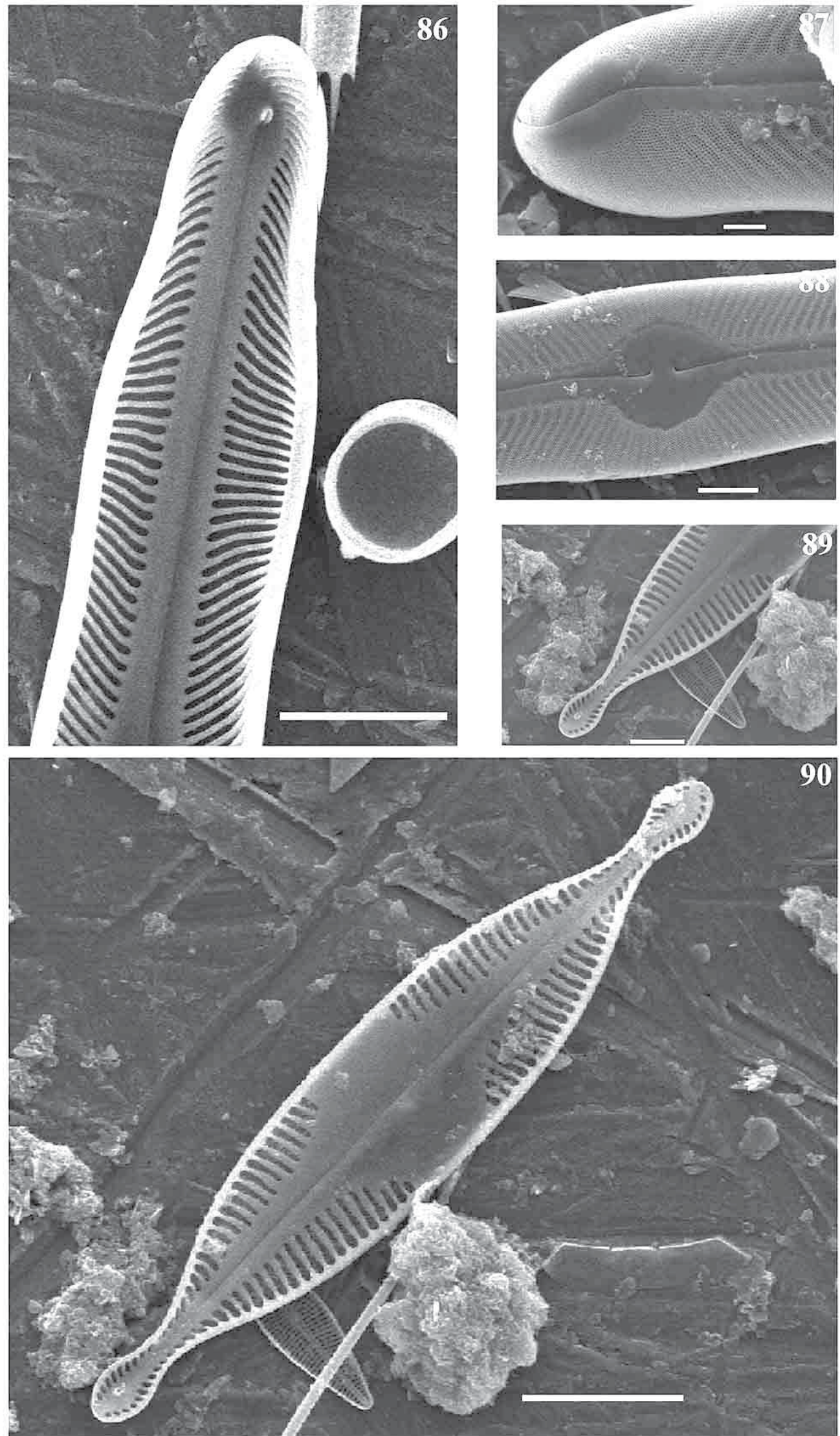

Figs. 86-90. Imagens em MEV. 86 - 88. Pinnularia tumescens.86. vista interna da extremidade distal da rafe; 87. vista externa da extremidade distal da rafe; 88. vista externa das extremidades distais da rafe na área central; 89, 90. P. tupensis. 89. vista interna da extremidade distal da rafe; 90. vista geral interna da valva. Barras: Figs. 86, $90=10 \mu \mathrm{m}$; Fig. $87=2 \mu \mathrm{m}$; Figs. $88,89=5 \mu \mathrm{m}$. 
Em síntese, dada a enorme extensão e elevada diversidade de ambientes aquáticos na Amazônia, há poucos estudos taxonômicos abordando o gênero Pinnularia, na região de modo geral e no estado do Pará em especial. Adicionalmente, a região tem sido considerada como um "hotspot" de diversidade para Pinnularia considerando a grande riqueza de espécies na região (Pereira et al. 2014). O corrente estudo vem contribuir com esses apontamentos e sugere ser relevante a realização de novos estudos para ampliar o conhecimento sobre o gênero Pinnularia na região Amazônica e na bacia do rio Tapajós, em especial.

\section{AGRADECIMENTOS}

À Coordenação de Aperfeiçoamento de Pessoal de Nível Superior (CAPES), a concessão de bolsa de Mestrado à primeira autora. Ao Programa de Pós-graduação em Recursos Aquáticos Continentais Amazônicos (PPGRACAM-Ufopa). Ao Centro de Microscopia Eletrônica da Universidade Federal do Rio Grande do Sul (UFRGS). À Universidade Federal do Oeste do Pará (Ufopa) e ao Museu de Ciências Naturais, Fundação Zoobotânica do Rio Grande do Sul (MCN-FZB/RS) pelo apoio logístico.

\section{REFERÊNCIAS}

Bicudo, C.E.M. \& Menezes, M. 2006. Técnicas para coleta, fixação, preservação e estudo. In Gêneros de algas continentais do Brasil (C.E.M Bicudo \& M. Menezes, orgs.). RiMa, São Carlos, p. 7-11.

Brassac, N.M. \& Ludwig, T.A.V. 2006. Diatomáceas da Bacia do Rio Iguaçu, Paraná, Brasil: Pinnularia e Caloneis. Hoehnea 33(2):127-142.

Cleve, P.T. 1894-1895. Synopsis of the naviculoid diatoms. Kungliga Svenska Vetenskapsakademiens Handlingar 26:1-235.

Díaz-Castro, J.G., Souza-Mossimann, R.N., Laudares-Silva, R. \& Forsberg, B.R. 2003. Composição da comunidade de diatomáceas perifíticas do Rio Jaú, Amazonas, Brasil. Acta Amazônica 33(4):583606.

França, A.A., Dunck, B., Rodrigues, L., Fonseca, B.M. \& Felisberto, S.A. 2017. Periphytic diatoms (Bacillariophyta) in streams from three Conservation Units of central Brazil: Pinnularia Ehrenberg. Hoehnea 44(4):524-538.

Fukushima, H. \& Xavier, M. B. 1988. Attached Diatom from the Negoro river, Amazonas, Brazil. Diatom 4:11-16.

Guiry M.D. in Guiry, M.D. \& Guiry, G.M. 2020. AlgaeBase. World-wide electronic publication, National University of Ireland, Galway. Disponível em http://www.algaebase.org. Acessado em 26.04.2020

Hustedt, F. 1965. Neue und wennig bekkante Diatomeen. IX Süsswassers Diatomeen aus Brasilien besondere des Amazonasgebiet. Internationale Revevue der Gesamten Hydrobiologie und Hydrographie 50(13):391-410.

Kociolek, J.P., Balasubramanian, K., Blanco, S., Coste, M., Ector, L., Liu, Y., Kulikovskiy, M., Lundholm, N., Ludwig, T., Potapova, M.,
Rimet, F., Sabbe, K., Sala, S., Sar, E., Taylor, J., Van de Vijver, B., Wetzel, C.E., Williams, D.M., Witkowski, A. \& Witkowski, J. 2020. DiatomBase. Disponível em http://www.diatombase.org. Acessado em 27.04.2020

Krammer, K. 2000. The Genus Pinnularia. In Diatoms of Europe. (H, Lange-Bertalot, ed.). Koeltz Scientific Books, Germany, v.1, 703 p.

Metzeltin, D. \& Lange-Bertalot, H. 1998. Tropical diatoms of South America I. In Iconographia Diatomologica. Annoted Diatom Micigraphs. (H. Lange-Bertalot. ed.). Koeltz Scientific Books, Germany, v.5, 695 p.

Metzeltin, D. \& Lange-Bertalot, H. 2007. Tropical diatoms of South America II. In Iconographia Diatomologica. Annoted Diatom Micigraphs. (H. Lange-Bertalot. ed). Koeltz Scientific Books, Germany, v.18, 877 p.

Patrick, R. \& Reimer, C. W. 1966. The Diatoms of United States: exclusive of Alaska and Hawaii. Academy of Natural Sciences, Philadelphia. $688 \mathrm{p}$.

Pereira, A.C., Torgan, L.C. \& Melo, S. 2012. Pinnularia Ehrenberg (Bacillariophyta) do curso inferior do rio Negro, Amazonas, Brasil: taxonomia e distribuição temporal. Acta Amazonica 42(3):305-313. . 2013. Pinnularia Ehrenberg (Bacillariophyceae) de um lago de inundação amazônico (lago Tupé, Amazonas, Brasil). Iheringia. Série Botânica 68 (1):91-101.

2014. Four new Pinnularia Ehrenberg (Bacillariophyta, Pinnulariaceae) species from Amazonian black water (Tupé Lake, Amazonas State, Brazil). Phytotaxa 158(2):154-168.

Pereira, A.C., Torgan, L. C., Burliga, A.L., Kociolek, J. P., Wetzel, C. E., Ector, L. \& Melo, S. 2015. Pinnularia caprichosa sp. nov.: a diatom from a black water Brazilian Amazon system. Phytotaxa 239 (3):280-286. Acta Limnologica Brasiliensia 21(2): 227-234.

Pereira, A.C., Torgan, L.C. \& Melo, S. 2017. Pinnularia (Bacillariophyta, Pinnulariaceae) dos cursos superior e médio do rio Negro e de tributários, Amazonas, Brasil. Boletim do Museu Paraense Emílio Goeldi, Ciências Naturais 12(1):49-74.

Raupp, S.V., Torgan, L. \& Melo, S. 2009. Planktonic diatom composition and abundance in the Amazonian floodplain Cutiuaú Lake are driven by the flood pulse. Acta Limnologica Brasiliensia 21(2):227-234.

Round, F. E., Crawford, R. M. \& Mann, D. G. 1990. The diatoms. Biology and morphology of the genera. Cambridge University Press, Cambridge. 747 p.

Schmidt A., Schmidt, M., Fricke, F., Heiden, H., Müller, O. \& Hustedt, H. 1874-1959. Atlas der Diatomaceen Kunde. 4 v., Tafeln 1-480. O. R. Reisland, Leipzig.

Simonsen, R. 1987. Atlas and catalogue of the diatom types of Fredrich Hustedt. J. Cramer, Berlin. 525p.

Stosch, H. A. Von. 1970. Methoden zur preparation keleiner oder zarter kieselelemente fur die elektronen und lichtmikroskopie, insbesondere von diatomeen und bei geringen materialmengen. Zeitschrift fur Wissenschaftlichen Mikroscopie 70:29-32.

Tremarin, P.I., Moreira-Filho, H. \& Ludwig, T.A.V. 2010. Pinnulariaceae (Bacillariophyceae) of the Guaraguaçu River, a coastal watershed in Paraná, Brazil. Acta Botanica Brasilica 24(2):335-353.

Uherkóvich, G. 1976. Algen aus den Flüssen Rio Negro und Rio Tapajós. Amazoniana 7(2): 191-219.

Wetzel, C.E. 2011. Biodiversidade e distribuição de diatomáceas (Ochrophyta, Bacillariophyceae) na bacia hidrográfica do Rio Negro, Amazonas, Brasil. Tese, 1876 f., Instituto de Botânica da Secretaria do Meio Ambiente, São Paulo. 